\title{
Cultured fish: integrative biology and management of domestication and interactions with wild fish
}

\author{
Kai Lorenzen ${ }^{1,2, *}$, Malcolm C.M. Beveridge ${ }^{3}$ and Marc Mangel ${ }^{4,5}$ \\ ${ }^{1}$ Fisheries and Aquatic Sciences, School of Forest Resources and Conservation, University of Florida, 7922 NW 71st St., Gainesville, FL 32653, \\ USA \\ ${ }^{2}$ Mote Marine Laboratory, 1600 Ken Thompson Parkway, Sarasota, FL 34236, USA \\ ${ }^{3}$ WorldFish Center, P.O. Box 51289, Ridgeway, Lusaka, Zambia \\ ${ }^{4}$ Center for Stock Assessment Research, Department of Applied Mathematics and Statistics, University of Califormia, Santa Cruz, CA 95060, USA \\ ${ }^{5}$ Department of Biology, University of Bergen, $\mathcal{N}-5020$ Bergen, Norway
}

\begin{abstract}
Fish aquaculture for commodity production, fisheries enhancement and conservation is expanding rapidly, with many cultured species undergoing inadvertent or controlled domestication. Cultured fish are frequently released, accidentally and deliberately, into natural environments where they may survive well and impact on wild fish populations through ecological, genetic, and technical interactions. Impacts of fish released accidentally or for fisheries enhancement tend to be negative for the wild populations involved, particularly where wild populations are small, and/or highly adapted to local conditions, and/or declining. Captive breeding and supplementation can play a positive role in restoring threatened populations, but the biology of threatened populations and the potential of culture approaches for conserving them remain poorly understood. Approaches to the management of domestication and cultured-wild fish interactions are often ad hoc, fragmented and poorly informed by current science. We develop an integrative biological framework for understanding and managing domestication and cultured-wild fish interactions. The framework sets out how management practices in culture and for cultured fish in natural environments affect domestication processes, interactions between cultured and wild fish, and outcomes in terms of commodity production, fisheries yield, and conservation. We also develop a typology of management systems (specific combinations of management practices in culture and in natural environments) that are likely to provide positive outcomes for particular management objectives and situations. We close by setting out avenues for further research that will simultaneously improve fish domestication and management of cultured-wild fish interactions and provide key insights into fundamental biology.
\end{abstract}

Key words: domestication, selection, plasticity, stocking, fisheries enhancement, captive breeding, supplementation, culture-based fisheries, aquaculture, escapes.

\section{CONTENTS}

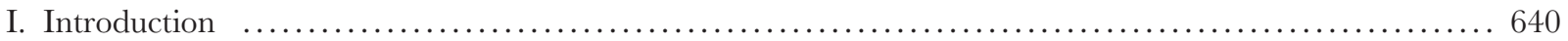

II. Framework for analyzing domestication and cultured-wild fish interactions $\ldots \ldots \ldots \ldots \ldots \ldots \ldots \ldots \ldots \ldots 61$

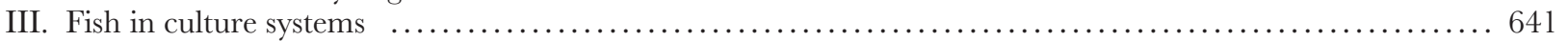

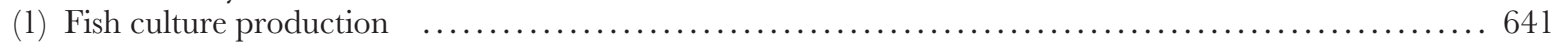

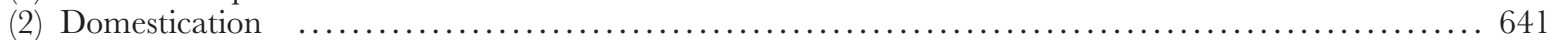

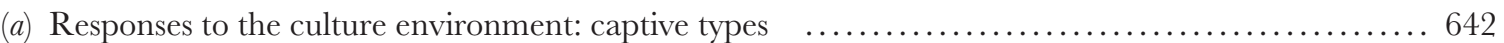

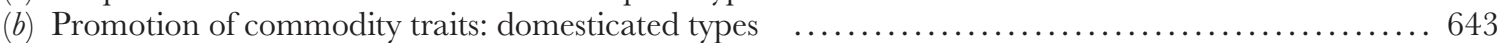

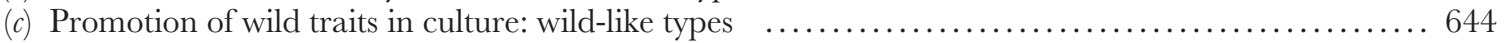

(d) Differentiated promotion of domesticated and wild-like traits: mixed types $\ldots \ldots \ldots \ldots \ldots \ldots \ldots \ldots 645$

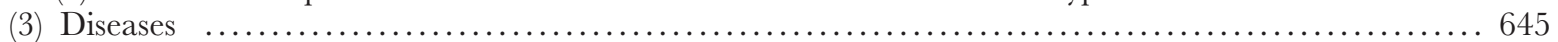

* Address for correspondence at address 1 (Tel.: (01) 352-273-3646; Fax: (01) 352-392-3672; E-mail: klorenzen@ufl.edu). 


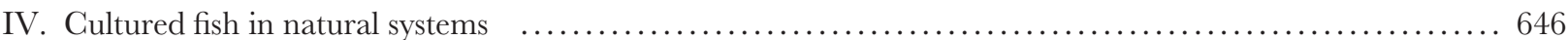

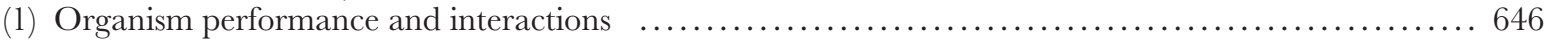

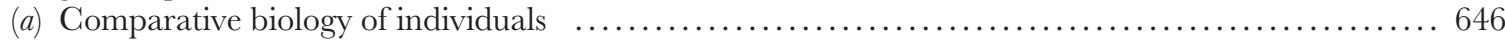

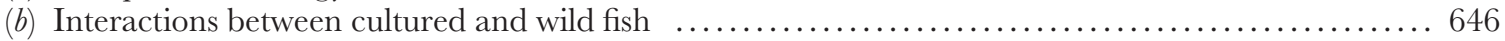

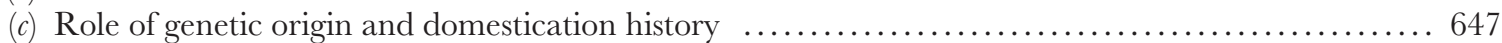

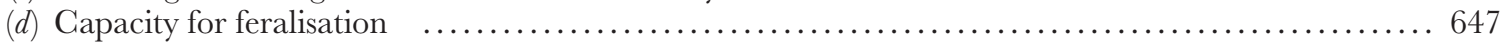

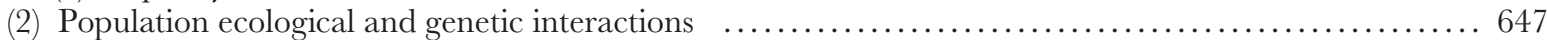

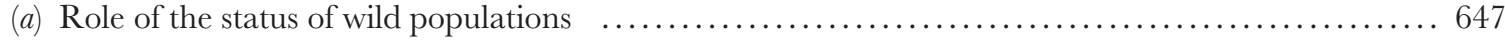

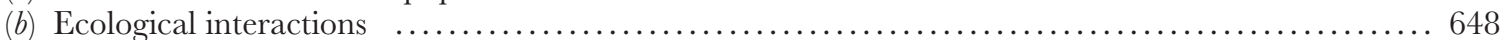

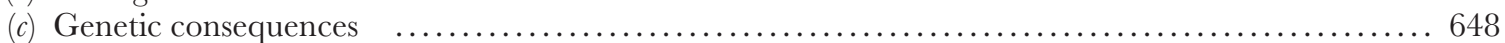

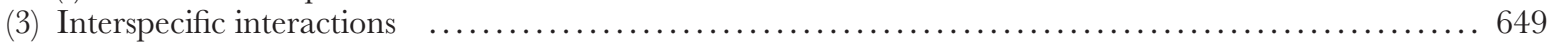

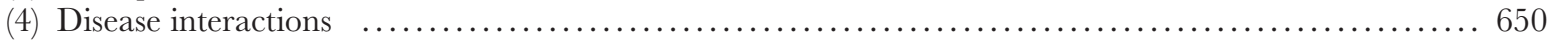

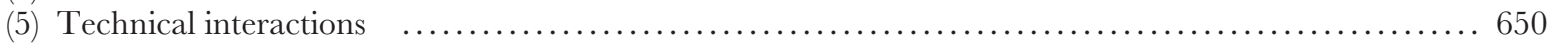

V. Integrated management of fish culture and cultured-wild fish interactions: a typology of systems $\ldots . . . .650$

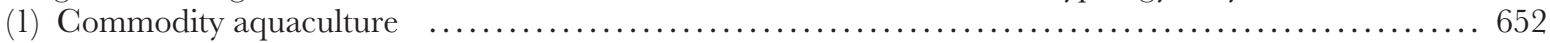

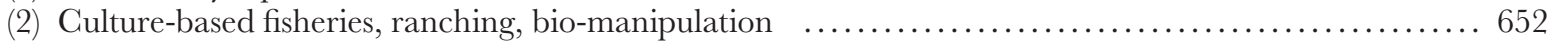

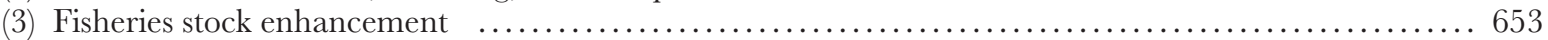

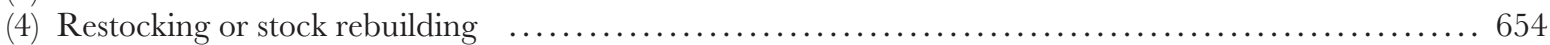

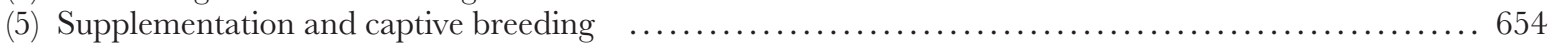

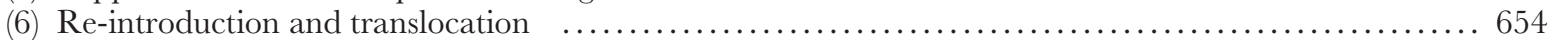

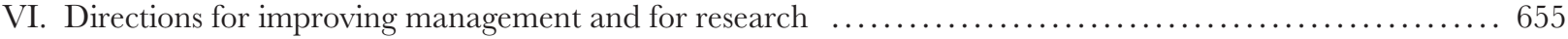

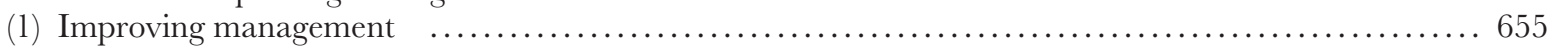

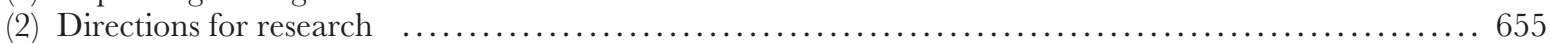

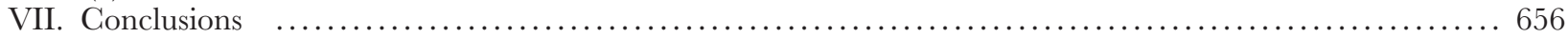

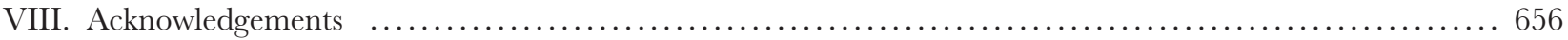

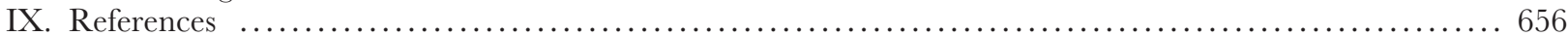

\section{INTRODUCTION}

Fish rearing in culture or captivity has expanded rapidly over the past decades. Fish culture for food alone has expanded tenfold since 1970 and now involves over 160 species (Tacon, 2003; Duarte, Marba \& Holmer, 2007; Bostock et al., 2010). In addition, fish are cultured for recreation, ornament, biomanipulation, conservation and restoration of threatened species, and for research (Welcomme \& Bartley, 1998; Utter \& Epifanio, 2002).

Rearing under culture conditions implies radical modifications of the organism's environment and often deliberate manipulations of its biology, e.g. through selective breeding. Cultured fish thus enter a process of domestication: a process of developmental and genetic change in response to culture. Domestication gives rise to organisms that perform better under culture conditions than their wild conspecifics and may express additional attributes desired by culturists. The flip side is that such organisms tend be less fit than their wild conspecifics when released into natural environments. Although many fish species have been brought into culture and thus subjected to a domestication process, very few can be considered fully domesticated in the sense that their morphology and physiology exhibit variation not seen in the wild and they would not survive without human protection (Balon, 2004; Bilio, 2008).

Cultured and wild fish populations interact widely and significantly. Cultured fish are being released on a very large scale, both accidentally and intentionally (McGinnity et al., 2003; Naylor et al., 2004; Laikre et al., 2010). The bulk of cultured fish are kept in ponds and cages from which fish may escape during floods or when containment structures are accidentally breached. Intentional releases of cultured fish for fisheries enhancement, conservation or restoration are widespread (Philippart, 1995; Welcomme \& Bartley, 1998; Lorenzen, 2008b). Even though fish undergoing domestication tend to perform less well in natural environments than their wild ancestors, they often survive sufficiently well to interact with wild fish ecologically and genetically. Such interactions may be problematic or positive. Problematic interactions include displacement of wild fish through ecological interactions, reductions in fitness and genetic diversity of populations subject to interbreeding between cultured and wild fish, changes in the dynamics of infectious diseases, and technical interactions such as increased fishing pressure on wild fish due to fisher's responses to fish stocking (McGinnity et al., 2003; Lorenzen, 2008b; Van Poorten et al., 2011). Positive interactions include increases in total population abundance that can support fisheries or counteract ecological and genetic risks in endangered populations (Hedrick et al., 2000; Hilderbrand, 2002). Longterm outcomes of cultured-wild fish interactions have proved highly variable and difficult to predict (Fraser, 2008; Araki \& Schmid, 2010). This is not surprising given that outcomes are influenced by complex and linked ecological and genetic processes and are highly sensitive to domestication effects in cultured fish, wild population characteristics, and release and fishing practices.

The current situation thus provides both an opportunity and a need for research on the biology of fish domestication 
and the interaction between cultured and wild fish. Effective management of domestication and of cultured-wild fish interactions requires an approach that is multi-dimensional and integrative: developing management systems that account for, and are differentiated by, overarching goals, culture systems and their effects on domestication processes characteristics of natural populations and ecosystems, and management of release and fishing in the natural environment. Our aim herein is to set out a framework for integrative analysis and to review current knowledge pertinent to this framework and its use in analysis and planning. We do so by setting out the general framework (Section II), reviewing culture and domestication processes (Section III) and cultured-wild fish interactions (Section IV), and developing a typology of alternative management systems (Section V). We close by identifying key conclusions and questions for further research.

Throughout this review we maintain a taxonomic focus on teleost fish, the dominant group of cultured aquatic animals and the primary focus of both research on domestication effects and applied conservation concerns over cultured-wild organism interactions in aquatic environments. Much of our discussion, however, is also likely to be relevant to cultured aquatic invertebrates.

\section{FRAMEWORK FOR ANALYZING DOMESTICATION AND GULTURED-WILD FISH INTERACTIONS}

A framework for analysing domestication and cultured-wild fish interactions is set out in Fig. 1. The framework illustrates schematically how the interaction of management practices with biological attributes and processes in the culture and natural systems leads to outcomes. It also illustrates key linkages between the culture and natural systems through transfer of organisms: assembly of founder populations in culture from natural populations, and release of cultured fish into natural populations and communities. Our review is organized principally around the biological attributes and processes set out in the central column of Fig. 1, because it is through these that management practices affect outcomes.

\section{FISH IN GULTURE SYSTEMS}

The culture facility, husbandry practices, genetic and health management influence overall production levels, the phenotypic and genetic quality of cultured fish, and their health. We review these influences in terms of the underlying processes of production, domestication and diseases, with a particular focus on domestication.

\section{(1) Fish culture production}

Although overall degree of control and production intensity vary widely between fish culture systems, all are essentially designed to confine fish within facilities, create environmental

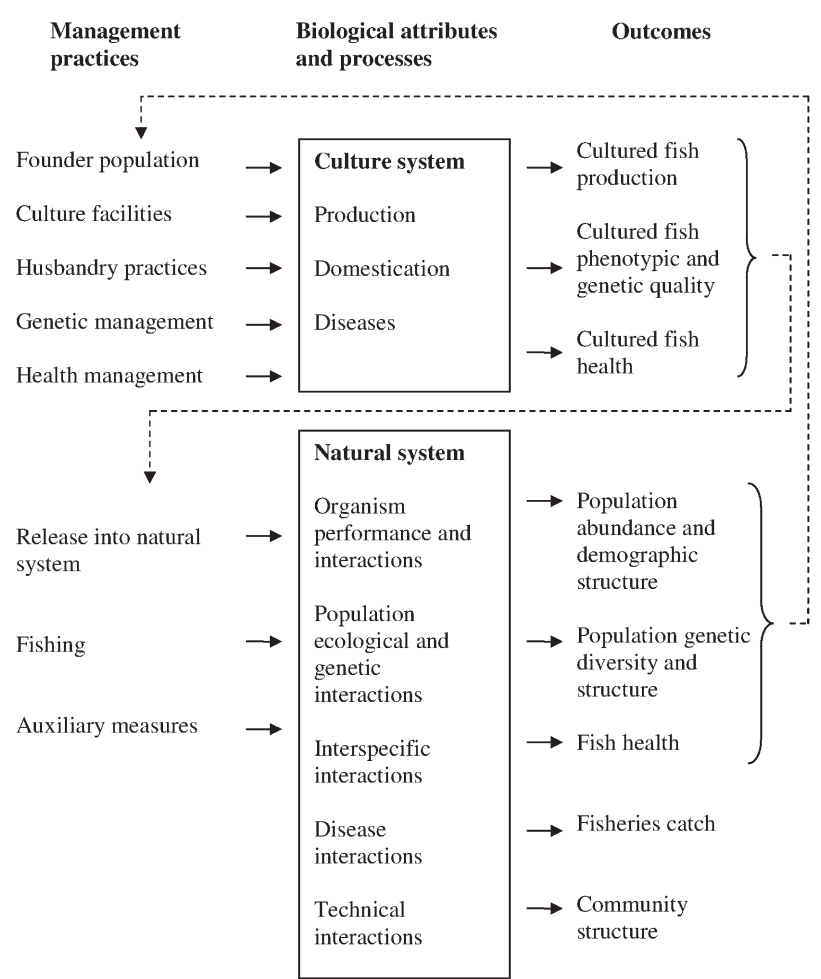

Fig. 1. Conceptual framework for analyzing domestication and cultured-wild fish interactions. Solid arrows indicate influences of management measures on biological processes and dashed arrows show key linkages between culture and natural systems through transfer of organisms.

conditions that are conducive to fish growth and survival, supply nutrients in the quantity and quality required by the cultured organism, and control predators and diseases. In well-managed systems, cultured fish grow at rates near their physiological maximum and suffer much lower mortality rates than in natural environments (Lorenzen, 1996, 2000b). External inputs of nutrients and removal of waste products allow fish to be cultured at densities and per-area production levels that may exceed those found in natural systems by orders of magnitude (Bostock et al., 2010; Welcomme et al., 2010).

\section{(2) Domestication}

Domestication is a process of change in the cultured organism that involves genetic changes occurring over generations and developmental effects recurring during each generation (adapted from Price, 2002). On the whole, domestication gives rise to organisms that perform better under culture conditions, and less well under natural conditions than their wild conspecifics.

Traditionally, animal domestication has been interpreted almost exclusively in terms of genetic change through natural and artificial selection (Clutton-Brock, 1987). However, recent interest in captive breeding of endangered species and in new domesticates has led to a greater appreciation of the role of developmental responses (Price, 2002). 
Developmental responses are particularly pertinent to the domestication of fish, which show much greater levels of phenotypic plasticity than higher vertebrates (Allendorf, Ryman \& Utter, 1987; Thorpe, 2004).

Here we describe as "genetic" all those mechanisms that affect the genotype: natural, sexual and artificial selection, inbreeding, drift, hybridisation, chromosome manipulations and genetic engineering. We summarize as "developmental" all those mechanisms that affect the expression of phenotypic traits within a given genotype. This includes broad effects also known as phenotypic plasticity or reaction norms, and very specific effects such as hormonally induced spawning or sex reversal. In both genetic and developmental mechanisms, we distinguish between inadvertent responses to culture conditions and deliberate manipulations. For example, inadvertent genetic responses arise from natural and sexual selection in the culture environment, while deliberate genetic manipulations arise from artificial selection (selective breeding) by the culturist. Genetic and developmental responses tend to occur together and often in the same general direction because reaction norms of phenotypic plasticity are in themselves the product of natural selection.

The relative contribution of genetic and developmental responses to observed patterns is often difficult to ascertain. Experimentally, this can be achieved by exposing fish of the same or closely related genotype to different environments to demonstrate developmental plasticity, and exposing fish of different genotypes to a common environment to show genetically based differentiation (Reisenbichler \& McIntyre, 1977; Conover, 1998; Khaw et al., 2009). However, even in well-designed experiments within-generation natural selection may be difficult to distinguish from developmental plasticity (Huntingford, 2004). Where pedigree information is available, the 'animal model' in quantitative genetics offers a way of partitioning variation into plasticity and selection components (Wilson et al., 2010).

We propose to distinguish four modes of domestication based on the degree to which cultured fish are subject to deliberate manipulations of their biology, and the intended outcome of such manipulations (types) (Fig. 2). By "types" we denote sets of phenotypes and genotypes that emerge through common processes, but may nonetheless differ due to specific details of the processes involved. The most basic mode of domestication is dominated by inadvertent responses to the culture environment, and leads to the evolution of captive types. Advanced modes of domestication involve targeted manipulations of the organism's biology away from the captive type. This may involve the promotion of traits desirable in aquaculture commodities to produce a range of fully domesticated types, promotion of the wild genotype and phenotype under culture conditions to produce or maintain wild-like types, or a mixed strategy. Domestication is a dynamic process: even under constant conditions the cultured organisms will continue to evolve for many generations. If culture conditions change, the domestication process will change too. A reduction in artificial selection pressure for example can result in the organism reverting

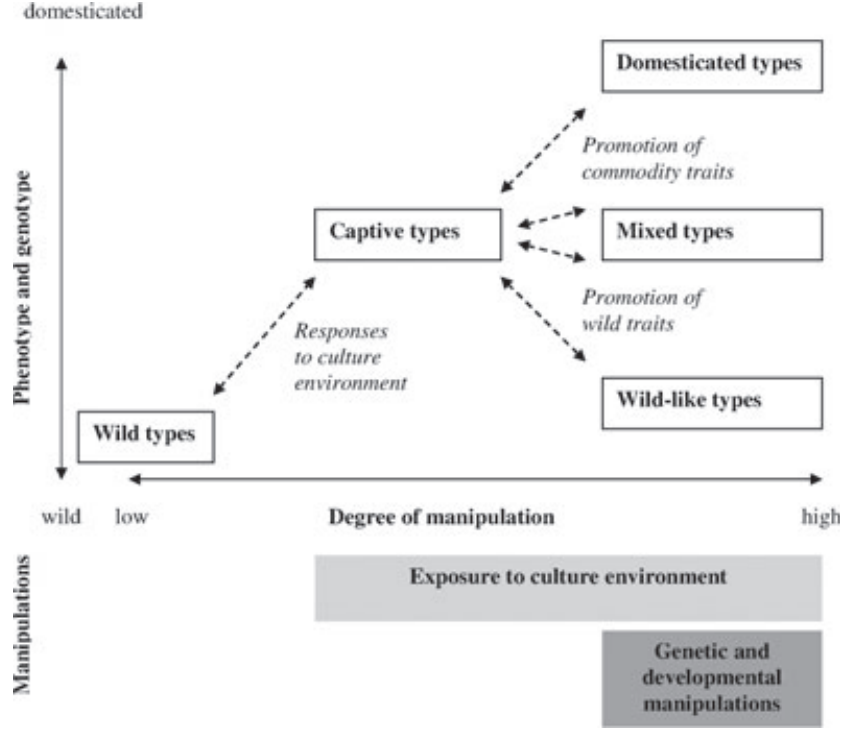

Fig. 2. Modes of domestication, indicating key mechanisms and endpoints towards which they modify the organism.

from a highly selected domesticated, to a captive type (though specific traits of such a captive type may differ from those of a captive type derived directly from wild ancestors).

\section{(a) Responses to the culture environment: captive types}

The basic mode of domestication is characterized by responses of the organism to a culture system which, on the whole, meets requirements of the fish better than the natural environment. The physical environment is maintained within the organism's physiological limits; feed is provided in good quality, quantity and in a predictable manner, and natural enemies controlled. Even so, technical limitations and economic considerations imply that conditions are generally less than ideal: the "pampering" of fish (Thorpe, 2004) is rarely perfect. Aquaculture systems tend to be smaller, more confined and less complex than natural environments and populations far more dense, affecting the frequency and nature of social interactions in ways that are not always beneficial to the fish (leading e.g. to frequent fighting or uneven access to feed; Huntingford, 2004). Feeds or environmental conditions including water quality may be suboptimal at particular stages in the life cycle, and exposure to microparasites such as viruses and bacteria can be extremely high (Murray \& Peeler, 2005; Pulkkinen et al., 2010). Overall therefore, the culture environment reduces pressure to adapt on many traits, but introduces new pressures on others.

A wealth of comparative studies on the biology of cultured and wild fish point to a set of consistent changes associated with responses to the culture environment. These include a general acceleration of individual development: cultured fish grow faster and metamorphose from larvae to juveniles, mature and show signs of senescence earlier than their wild counterparts (Thorpe, 1991; Lorenzen, 2000b). This ontogeny is consistent with the idea that transitions such 
as maturation occur as soon as fish have accumulated the necessary resources (Policansky, 1983). In line with the accelerated life cycle, physiological longevity may be reduced in captivity (Linnen, Tatar \& Promislow, 2001), but this effect tends to be more than outweighed by the control of natural enemies so that survival rates in culture are much higher than in the wild (Lorenzen, 1996). The culture environment also modifies behavioural traits (Huntingford, 2004). Foraging, anti-predator and reproductive behaviour tend to be reduced in complexity and effectiveness. Territorial behaviour is effectively suppressed or substantially altered in many species kept in aquaculture facilities at high density. Aggressiveness is often enhanced, particularly where food is distributed in a localised and predictable manner. Aggressive behavioural types perform well in simple environments and under high density (such as in culture), but unaggressive types tend to be more flexible and do better under conditions of environmental complexity and uncertainty (Huntingford, 2004). Responses to the culture environment thus give rise to a coherent 'domestication syndrome': life-history patterns that reflect a change in resource allocation towards growth and reproduction but away from resource conservation, foraging and predator avoidance functions that enhance fitness in complex and unpredictable natural environments (Hammer, 1984; Beilharz, Luxford \& Wilkinson, 1993; Thorpe, 2004).

Responses to culture involve both genetic and developmental mechanisms. Increased growth rate and reduced behavioural complexity, for example, may result from phenotypic plasticity and become apparent within weeks or months of an organism's transfer from a natural to a culture environment, but become more pronounced in successive generations due to inadvertent selection (Lorenzen, 2000b; Metcalfe, Valdimarsson \& Morgan, 2003; Huntingford, 2004). Genetic adaptation to captivity appears to involve alleles that are rare and deleterious in the wild but are favoured, or at least not selected against, in captivity (Frankham, 2008). In addition to genetic adaptation to captivity, captive populations often experience loss of genetic diversity (heterozygosity, allelic diversity) due to low effective population size and consequent genetic drift and inbreeding. The latter effects can be mitigated against relatively easily through appropriate brood stock management, but practical constraints or ignorance mean that this is often not done (Verspoor, 1988; Kincaid, 1995; Norris, Bradley \& Cunningham, 1999). Captive types often show traits that are beneficial to culture operations, even though they have not been deliberately promoted. With the exception of maturation, accelerated development is seen as a bonus in aquaculture because it allows faster turnover and thus lowers production costs and risks (Thorpe, 2004).

\section{(b) Promotion of commodity traits: domesticated types}

Advanced domestication involves the promotion of commodity traits through selective breeding and other genetic manipulations as well as targeted interventions in developmental processes. We summarize as "commodity traits" all traits that culturists find desirable in the cultured fish. In combination with reproductive technologies that weaken the link between reproductive output and many morphological and physiological traits, advanced domestication can give rise to traits that are commercially advantageous but nonadaptive even within a culture environment.

Fairly comprehensive selective breeding programmes are in operation for several species of fish including Atlantic salmon (Salmo salar), rainbow trout (Oncorhynchus mykiss), channel catfish (Ictalurus punctatus) and Nile tilapia (Oreochromis niloticus) (Dunham et al., 2001). Genetic variation in quantitative traits such as growth is higher in cultured fish than in domesticated mammals, but this difference may reflect loss of variation under intensive selection of the latter rather than a fundamental difference between taxa (Dunham et al., 2001). Artificial selection programmes have been successful in improving growth, feed conversion, and disease resistance in a number of farmed fish species (Dunham et al., 2001; Cipriano et al., 2002; Hulata, 2002; Jonsson \& Jonsson, 2006). Selection programmes have also long been carried out for ornamental fish (Balon, 2004), and most recently zebrafish (Danio rerio) lines have been specifically selected for biomedical research (Keller \& Murtha, 2004). Selection for particular traits often causes correlated changes in other traits which may or may not be desirable. This genetic correlation may arise from linked gene complexes, pleiotropy (where a single gene affects several traits), or selection of genotypes favouring allocation of finite resources to different functions (Beilharz et al., 1993; Thorpe, 2004).

Genetic engineering offers the potential for generating new diversity by introducing genes from reproductively incompatible backgrounds often to achieve a very specific constitutive gain of function (Gepts, 2002). The expression and inheritance of transferred genes depends on their (uncertain) integration point in the host organism's genome, as well as its genetic background and the environment (Maclean \& Laight, 2000; Devlin et al., 2001; Kapuscinski et al., 2007). Hence genetic engineering may contribute to, rather than replace, classical selection and testing programmes. Transgenic fish have so far been developed mostly for growth enhancement and for ornamental purposes. However, potential applications include cold and salinity tolerance, disease resistance, sterility and metabolic modifications including the production of pharmacological proteins (Maclean \& Laight, 2000).

Hybridization and chromosome set manipulations are more widely used in fish than in higher vertebrates. The same mechanisms have long contributed to the development of plant cultivars (Gepts, 2002; Gepts \& Papa, 2002). Interspecific hybrids are widely produced for their quantitative and qualitative traits including improved growth, harvestability, and environmental tolerance. Hybrids often combine desirable traits of two species. In contrast to hybrids between higher vertebrates only some, but by no means all, fish hybrids are sterile (Bartley, Rana \& Immink, 2001). Triploidisation may be used to induce sterility (Dunham, 1990; Piferrer et al., 2009). Chromosome set manipulations also have been used, in conjunction with complex breeding 
schemes, to produce genetically monosex offspring (Mair et al., 1997).

Developmental manipulations may be employed to control reproduction (either inducing or preventing it) and are therefore central to both enabling domestication and managing domesticated fish in the wild even though they do not in themselves modify the genetic makeup of domesticates. Environmental modifications such as photoperiod, temperature, hormonal and feed manipulations are applied variously to delay or induce maturation (Thorpe, 2004), and many fish species do not complete gamete production in captivity without such manipulations (Bromage, 1995; Zohar \& Mylonas, 2001). Direct developmental manipulations include hormone treatment of early life stages to induce sex reversal or sterility (Dunham, 1990).

\section{(c) Promotion of wild traits in culture: wild-like types}

By default, biological responses to the culture environment lead to the emergence of captive types as described above. This is clearly undesirable in conservation-oriented fish culture for live gene banking, supplementation and restoration where maintenance of the wild type is an explicit goal. Maintenance of certain wild-type attributes may also improve the performance of fish released into natural environments for purposes other than conservation. While it is virtually impossible completely to avert responses to captivity, management approaches have been developed to produce wild-like types that maintain or re-establish certain characteristics of the wild types. In general such approaches carry costs in terms of reductions in culture intensity or implementation of management practices additional to those required purely for culture production.

The production of wild-like types in culture requires attention to both the sampling of fish for the founder population and its subsequent management in captivity. Founder populations should maintain the (neutral and adaptive) variation found in wild populations and encompass sufficient diversity of genotypes and life-history phenotypes to allow re-establishment of viable populations in the wild (see also Section IV.2c). The latter condition of course may be difficult to fulfil where the wild population is already in a degraded state.

Once the captive population is established, both environmental and genetic management are important to promote maintenance of wild characteristics. The holistic solution of providing a near-natural environment for fish to live in and possibly reproduce can maintain natural selection and developmental cues. However, this approach is often impractical. It may also negate the survival advantage of fish in culture, which often is an important reason for bringing fish into captivity in the first place. Far more interventionist genetic resource management and developmental manipulations are usually required.

Genetic management of the captive population is aimed at conserving genetic diversity while also minimizing genetic adaptation to the culture environment (Frankham, 2008; Fraser, 2008). Genetic adaptation in captivity is positively related to genetic diversity, effective population size, number of generations and the intensity of (natural or artificial) selection [see Frankham, Ballou \& Briscoe (2002) for a quantitative analysis and discussion]. The most effective way of minimizing both loss of genetic diversity and domestication selection is to minimize the time spent in captivity. In many stock enhancement, supplementation or rebuilding programmes, broodstock consists of wild fish only (Bartley, Kent \& Drawbridge, 1995; Hedrick et al., 2000). This approach is effective in minimizing the potential for loss of genetic diversity and for domestication selection. Some domestication selection will still occur within the captive rearing phase, and after release when natural selection may favour fish that performed well (grew large) in the culture environment (Reisenbichler, Utter \& Krueger, 2003). However, the scope for evolutionary change is inherently limited within a single generation as compared to multiple generations. In assembling broodstock from wild-caught animals, care must be taken not to include released cultured fish as this would create an integrated hatchery-wild population with a combined selection regime likely to reduce fitness in the wild, unless the contribution of hatchery fish to the population is very small (Ford, 2002; Goodman, 2005).

Where captive populations need to be maintained for extended periods, it may still be possible to minimize the number of generations and thus, diversity loss and domestication selection, by breeding from older fish. Because both total fecundity and quality of eggs and larvae in fish tend to increase with parental age, there are likely to be fewer constraints on this strategy than in mammals. Cultured fish suffer much lower mortality rates than wild fish due to reduced predation and are likely therefore to live longer on average (Lorenzen, 1996). It may thus be advantageous to take measures that may delay maturation and senescence, such as feeding low rations (Thorpe, 2004). Cryopreservation of sperm (Chao \& Liao, 2001) offers some limited scope for extending effective generation length. While minimizing generations in captivity is an effective way of minimizing genetic adaptation to captivity, the rate of change in adaptive traits is likely to be greatest within the first generations when wild fish are exposed to the culture environment and to decline over time as animals become more adapted.

Where populations must be maintained in captivity for multiple generations, there is an inherent trade-off between the goals of maintaining diversity and minimizing adaptation because the potential for genetic adaptation is directly proportional to the heritable genetic diversity (Woodworth et al., 2002; Frankham, 2008). Arguably, conservation of genetic diversity is more important than avoidance of adaptation to the culture environment: if adequate diversity is maintained, it should provide sufficient reserve for feralization (re-adaptation to the natural environment). However, adaptation to the culture environment can greatly increase the effort required to establish a feral population. Hence a compromise strategy that minimizes the combined effects of inbreeding, drift and inadvertent selection may be most successful in maintaining the wild genotype. The most 
commonly advocated approach is to combine factorial mating designs (maximising genetic diversity of offspring) and equalisation of family size (minimizing inadvertent selection), but this design may be difficult and expensive to implement and involves sacrificing a large proportion of progeny (Waples, 1999; Frankham et al., 2000; Ponzoni et al., 2010). Hence there is usually a trade-off between conserving the genetic makeup of the captive population and achieving high reproductive rates (Fiumera et al., 2004). An alternative that has been proposed but not yet fully evaluated for fish is to divide the captive population into small subpopulations which may be group-bred, and rotate some animals between sub-populations once inbreeding becomes significant (Margan et al., 1998; Frankham, 2008; Fraser, 2008).

Whereas culture environments are too different from the natural environments to make maintenance of a 'natural' regime of natural selection a realistic prospect, there is some debate as to the possibility of maintaining sexual selection by allowing mate choice in cultured fish. While breeders are selected individually by culturists in many freshwater culture systems, group spawning with the potential for mate choice is often employed in marine culture systems (though group sizes tend to be small compared to those found in the wild). Maintaining sexual selection in culture could be beneficial if mate choice is linked to heritable fitness or parental effort (Wedekind, 2002; Theriault et al., 2011).

Developmental manipulations to promote wild traits are important to raise performance after release, and some such manipulations may also reduce selection for culture traits. Typical manipulations include physical environmental features (e.g. temperature, water currents), nutrition, and feeding practices (Tanaka et al., 1998). Environmental enrichment (Berejikian et al., 2000), life-skills training (Brown \& Laland, 2001) and soft release strategies (Brown \& Day, 2002) can successfully promote behavioural skills that may increase survival of released fish. The fact that cultured fish respond readily to habitat enrichment and life-skills training by displaying "wild" behavioural patterns (Brown \& Laland, 2001) attests to the maintenance of their enormous developmental plasticity. Exposure to variable spatial and foraging cues in the hatchery environment provides fish with enhanced behavioural traits that may be associated with improved survival in the wild (Braithwaite \& Salvanes, 2005). While many such manipulations have been shown to promote wild-like traits in laboratory tests, their effectiveness at achieving the ultimate goal, increased lifetime fitness in the wild, has not been widely tested. Results so far have not shown very large effects on long-term survival (e.g. Fuss \& Byrne, 2002).

\section{(d) Differentiated promotion of domesticated and wild-like traits: mixed types}

In certain uses of cultured fish in the wild, such as culturebased fisheries/ranching or those fisheries enhancement programs where wild and hatchery-reared stock components can be separated, it may be advantageous in principle to promote a mixture of commodity and wild-like traits. Salmon enhancement programs in which hatchery stocks are reproductively separated from wild stocks increasingly aim to develop stocks that perform well in the culture environment in early life and are adapted to the local natural environment in the post-release phase of their lifecycle (Mobrand et al., 2005). Given the consistency of the domestication syndrome and its detrimental effect on fitness in the wild (see Section IV), there are likely to be constraints on promoting adaptation to such contrasting environments in different life stages. Experiments show, however, that selective breeding for return rate of ranched salmon can be effective (Jonasson, Gjedre \& Gjedrem, 1997). The full-lifecycle performance of mixed-type stocks in enhancement programs may well exceed that of captive or domesticated types (which perform poorly in the wild) or that of wild-like types (which perform poorly, or are demanding to produce in culture).

\section{(3) Diseases}

A variety of non-infectious pathologies such as spinal deformities, cataracts, fin erosion or liver damage occur in cultured fish (Tacon, 1992; Ashley, 2007). Many such conditions are related to inadequate environmental conditions or nutritional deficiencies and are prevalent in newly cultured species or newly developed culture systems, but become rare once husbandry practices are well developed.

Transfer of parasites (used here in the broadest sense, encompassing microorganism, protozoa and metazoa) from wild to cultured fish occurs through infected founder populations and more commonly, transmission across the boundaries of environmentally open culture systems (McVicar, 1997; Kurath \& Winton, 2011). Confinement of fish in culture facilities greatly reduces transmission of metazoan parasites with complex life cycles (because intermediate or final hosts are typically absent), but provides ideal conditions for transmission of parasites with direct life cycles including bacteria, viruses, many protozoa and some metazoans such as sea lice (Murray \& Peeler, 2005). Parasites with direct life cycles frequently establish strains that persist within culture systems and, due to high host densities and other factors, may evolve greater virulence than the original strains found in low-density wild fish populations (Pulkkinen et al., 2010; Kurath \& Winton, 2011), Control of parasites with direct life cycles through a variety of preventive means and treatments is thus of utmost importance in most fish culture systems. Key measures include prevention of pathogen entry by closing culture facilities to the environment, discontinuous (batch) culture interspersed with disinfection of facilities or fallowing of sites to break transmission cycles, pathogen screening and prevention of movement of infected animals, vaccination, and chemotherapy (Owens, 2003). The choice of control measures and their effectiveness vary greatly between culture systems, with acceptable outcomes ranging from elimination of parasites to their maintenance at levels that do no cause excessive harm. 


\section{GULTURED FISH IN NATURAL SYSTEMS}

Releases of cultured fish into the natural environment may be accidental or deliberate and vary in magnitude (numbers), life stage/size, phenotypic and genetic quality, and health of culture fish. (Fig. 1). Fishing may be carried out at different intensities and may be more or less selective for fish size and cultured or wild origin. Sometimes, releases are accompanied by auxilary measures such as habitat restoration or control of non-native species. Together releases, fishing and auxiliary measures may influence wild fish abundance and demographic structure, genetic diversity and structure, health, fisheries catch, and community structure. We discuss these interactions by focusing on the key processes and attributes of organism performance and interactions, population-level ecological and genetic interactions, interspecific interactions, disease interactions and technical interactions.

\section{(1) Organism performance and interactions}

\section{(a) Comparative biology of individuals}

The comparative biology of released cultured and wild fish has been extensively studied, and some fairly consistent patterns have emerged (Gross, 1998; Fleming \& Petersson, 2001; Weber \& Fausch, 2003). Most studies have involved captive types, from both local and translocated populations, and have focused on first-generation released fish.

Cultured fish released into the wild tend to differ from their wild conspecifics in a wide range of morphological, behavioural, physiological, and ecological attributes. Released cultured fish tend to move more and show higher levels of activity and aggression than wild conspecifics but are less adept at foraging, resulting in high energy expenditure and low intake (Sosiak, Randall \& McKenzie, 1979; Ersbak \& Haase, 1983; Nostvik \& Pedersen, 1999). Accelerated development and increased aggression may confer an initial advantage on released cultured fish, but this is usually offset by poorer long-term performance (e.g. McGinnity et al., 2003). The susceptibility of released cultured fish to predation is often increased, due to morphological features such as conspicuous colouration (Fairchild \& Howell, 2004), use of habitats subject to high predation risk, and poorly developed anti-predator behaviour (Olla, Davis \& Ryer, 1998; Malavasi et al., 2004). Cultured fish may also be more susceptible to capture by fishing gear than their wild conspecifics (Mezzera \& Largiader, 2001). These attributes of cultured fish in the wild are broadly consistent with the domestication syndrome described in Section III.3: a decline in biological functions required to perform in complex and unpredictable environments. Being based on multiple behavioral, physiological, ecological and morphological attributes that are plastic on different timescales, differences between released cultured fish and their wild conspecifics tend to diminish over the lifetime of the released animal, but some genetically based differences may be measurable for multiple generations.
Natural mortality rates of released cultured fish are highly variable, but substantially higher on average than those of wild conspecifics of similar size (Lorenzen, 2000a; Fleming \& Petersson, 2001). Recent studies have shown that second-generation offspring of cultured fish spawned in the wild survive better than first-generation released fish, but remain less fit than fish of wild parentage (Araki et al., 2007a; Araki, Cooper \& Blouin, 2007b).

The reproductive ecology of cultured fish released into the wild often differs substantially from that of wild conspecifics. In salmonids, where reproductive ecology has been extensively studied, cultured fish differ in terms of the timing of breeding, the selection of nest sites, courting behaviour and competitive ability (Fleming \& Petersson, 2001; Weir et al., 2004). The result is that, in general, cultured fish show lower reproductive success than wild fish (Fleming \& Petersson, 2001; McGinnity et al., 2003). In addition, due to the biological differences mentioned, the degree of interbreeding with wild fish is often lower than expected from the relative abundance of the parent types (Fleming \& Petersson, 2001). Reproductive fitness of wildborn offspring of cultured fish tends to improve relative to that of first-generation released fish, but remains below that of wild fish (Araki, Cooper \& Blouin, 2010).

Sterility (usually induced by hormone treatment in early life stages or triploidisation) offers a relatively straightforward way of preventing interbreeding and thus, direct genetic interactions between cultured and wild fish. Relatively little is known about the performance and, in particular, residual spawning behaviour of sterile fish in the wild. There is evidence that sterile fish can, in some cases, interfere with spawning of wild fish and thus reduce their reproductive success (Piferrer et al., 2009).

\section{(b) Interactions between cultured and wild fish}

Most differences in the ecology of released cultured fish and their wild conspecifics are expressed regardless of whether individuals of the two types interact. However, where interactions do occur, they may be asymmetric and thus further modify relative performance. In most cases where behavioural interactions between released cultured and wild fish have been studied in natural environments, wild fish dominate interactions and tend to emerge better from them than their cultured counterparts (Huntingford, 2004). In culture systems and other artificial environments including laboratory settings often used to study culturedwild fish interactions, cultured fish more often dominate interactions (Huntingford, 2004). The test environment is thus a key factor to consider when studying cultured-wild fish interactions or interpreting results from such studies. Care must be also be taken when extrapolating from shortterm to longer term interactions. For example, cultured fish often are more aggressive than wild fish initially, but less good at acquiring resources in the longer term. 


\section{(c) Role of genetic origin and domestication history}

The ecology of cultured individuals in the wild is strongly influenced both by their genetic origin and the domestication process they have experienced whilst in captivity. Cultured fish from local populations tend to perform better on most criteria than those that have been translocated (Reisenbichler, 1988; McGinnity et al., 2003; Araki et al., 2008). Populations that have been cultured for only short periods tend to perform better than those cultured for many generations, but significant impacts are usually evident even after short periods in captivity (Reisenbichler \& McIntyre, 1977; SRSRP, 2004; Araki et al., 2007b). This suggests that on the whole, progressive domestication leads to a progressive loss in post-release fitness. Promotion of commodity traits through selective breeding may be expected to reduce fitness in the wild further, while minimising genetic adaptation to captivity and promoting wild-like traits should have the opposite effect. Empirical evidence for these effects however is scant and inconclusive. Testing of fitness in the wild or attributes relevant to it is not commonly carried out in selective breeding programmes for commodity traits. Evidence for positive impacts on post-release fitness of measures to promote wild-like types in culture is based mostly on morphological, physiological or behavioural indicators measured in short-term experiments rather than direct measurement of fitness in the wild.

\section{(d) Capacity for feralisation}

The performance of cultured fish in the wild tends to be poorest immediately after release, with observed differences diminishing as a result of developmental and genetic adaptation. Behaviour may adapt more rapidly, possibly as a result of learning, than morphology and colouration (Brown \& Laland, 2001; Fairchild \& Howell, 2004). Providing that initial fitness is sufficient to allow survival and reproduction, released fish may establish feral populations in the wild. The question of the extent to which cultured populations retain the genetic reserve to re-adapt to natural habitats is crucial to conservation aquaculture but insufficiently researched (Utter, 2004). Certainly, there is evidence that non-adaptive traits can be maintained over prolonged periods in modified environments, possibly due to genetic correlations with adaptive traits (Thrower, Hard \& Joyce, 2004). Widespread naturalisation of alien fish following escape from aquaculture facilities provides evidence that feralisation occurs readily even when no particular measures are taken to preserve the wild phenotype in culture (Welcomme, 1988). Feralisation of alien species may be facilitated by particular niche opportunities not available to native species recolonising ancestral habitat (Shea \& Chesson, 2002). Successful reintroduction programmes suggest that reserve for readaptation can be maintained and that sufficient initial fitness combined with high release numbers can kick-start the feralisation process (Philippart, 1995; Young et al., 2002).

\section{(2) Population ecological and genetic interactions}

Population-level ecological interactions occur as a result of the increase in population abundance at certain life stages associated with any release, and from differences in the biology of cultured and wild fish which have a modifying effect on the nature and strength of interactions. Ecological interactions have genetic consequences where cultured and wild fish interbreed (direct genetic interactions), or where the ecological interactions alter the selection regime (indirect genetic interactions). Interactions at the population level are thus dependent on the state of the wild population (abundance in absolute terms and as a fraction of carrying capacity, and genetic population structure and integrity) and the extent and quality of releases (abundance, rate of continued releases, genetic and phenotypic quality) (Weber $\&$ Fausch, 2003).

\section{(a) Role of the status of wild populations}

Several ecological and genetic attributes of wild fish populations are important determinants of the way in which released cultured fish interact with them. (1) Abundance of the population in absolute numbers. Populations that are small in absolute numbers (fewer than a few tens or hundreds) are prone to extinction from demographic stochasticity, and may also rapidly lose genetic diversity. (2) Abundance relative to carrying capacity, which affects the nature and strength of density-dependent processes. Populations that are at a large fraction of carrying capacity show compensatory density dependence in various lifehistory traits, while populations that are at a low fraction of carrying capacity (below 15\%) may show depensatory density dependence (Allee effects) (Liermann \& Hilborn, 2001; Rose et al., 2001). (3) Genetic diversity and population structure. Genetic diversity in wild fish is conserved by relatively large absolute effective population sizes, typically about $10 \%$ of the census size (Frankham, 1995). Neutral and adaptive genetic variation are spatially structured within the distribution area. Significant adaptive variation in particular may be present at small spatial scales (Conover et al., 2006; Mehner et al., 2009). Maintaining this variation is crucial to maintaining population abundance and fisheries yields under environmental variation (Hilborn et al., 2003). (4) Extent to which natural genetic population structure has been modified by human interference. Habitat alterations or selective harvesting may affect levels of gene flow among population segments and exert new selection pressures (Hutchings \& Fraser, 2008). (5) Temporal changes in all of the foregoing. Populations may undergo rapid changes in ecological or genetic status. Such changes can interact in a cataclysmic way in declining populations where multiple threats including demographic stochasticity, depensatory density dependence, and modification of genetic structure combine to drive the population towards extinction (Caughley, 1994). 


\section{(b) Ecological interactions}

In wild populations that are large in absolute numbers and as a fraction of carrying capacity, intraspecific ecological effects involve predominately direct or apparent (predatormediated) competition. Predation between cultured and wild conspecifics may become important in piscivores if cultured fish differ substantially in size from wild fish of the same life stage, but this has been little studied. Direct or apparent competition results in compensatory density dependence, which in fish is manifested mostly in mortality in juveniles and in growth and reproductive parameters in older fish (Rose et al., 2001; Lorenzen, 2008a). Population abundance is regulated predominantly by juvenile density-dependent mortality in many fish populations, but density-dependent growth and reproductive parameters in older (recruited) fish can also exert a strong and sometimes dominant regulatory effect (Lorenzen, 2008a). Addition of cultured fish prior to the dominant regulatory phase in the life cycle will cause strong compensatory responses in vital rates during that phase and thus reduce wild fish abundance. In stocks regulated primarily by juvenile density-dependent mortality, releases of large juveniles can raise overall biomass beyond natural carrying capacity, but this is not the case where regulation in the recruited phase is dominant. In either case, releases into populations that are at a low fraction of carrying capacity can increase overall abundance towards carrying capacity, but some compensatory responses in vital rates affecting both the stocked and wild population components are likely to occur (Lorenzen, 2005). The magnitude of these responses may vary from virtually none to complete compensation, and will typically be intermediate because compensatory processes tend to operate continuously over a wide range of densities rather than as a discrete switch from 'no density dependence' to complete compensation. As may be expected from these theoretical considerations, empirical evidence for replacement of wild by released cultured fish is variable $(\mathrm{Li}$ et al., 1996; Hilborn \& Eggers, 2000; Sharma et al., 2006). Of course, interactions between wild and released cultured fish are not limited to the current generation. Where released cultured fish contribute to the spawning stock, their offspring will be represented in the next generation where they will run the full gamut of regulatory processes alongside the offspring of wild spawners. Population modelling suggests that this may result in partial replacement of fish of wild parentage by fish of cultured or mixed parentage, to a degree determined by the relative abundance and relative fitness of both types (Lorenzen, 2005). High or continuous accidental or intentional releases may lead to complete replacement of the wild by cultured or feral populations, whether or not the populations interbreed (Ford, 2002; Lorenzen, 2005; Hindar et al., 2006).

Similar competitive interactions will occur where wild populations are small in absolute numbers, yet not depressed far below environmental carrying capacity: a situation found in some freshwater populations. However, in such populations demographic stochasticity presents a threat to population persistence and release of additional fish may be beneficial despite eliciting a compensatory response (Hilderbrand, 2002). Populations that are depleted far below carrying capacity may suffer depensatory density dependence regardless of absolute numbers, either "trapping" the population at low abundance or leading to continued decline (Liermann \& Hilborn, 2001; Walters \& Kitchell, 2001). In such populations, release of cultured fish could increase abundance to levels where depensation does not occur and thus kick-start population recovery. However, empirical evidence for beneficial demographic effects of releases on very small and declining natural populations is limited.

Maladaptation of cultured fish, manifested in lower vital rates relative to the wild type, reduces the threat of displacement of the wild by the cultured population, with or without genetic introgression. The effect of maladaptation on the productivity of a mixed wild and cultured population, however, is greatest at intermediate levels of maladaptation: well-adapted cultured fish are more likely to displace wild fish but do not affect mixed population productivity, while poorly adapted cultured fish contribute little to the mixed population and have little impact on its wild component (Lorenzen, 2005). The detrimental productivity effect is greater where the wild and cultured populations interbreed than where genetic mixing is avoided. The magnitude of impacts on wild population abundance and productivity of course also depends on the relative abundance of the populations: even poorly adapted fish can have a large impact if released in very large numbers and over long periods of time. Empirical studies have found evidence for reduced productivity in some mixed wild-cultured salmonid populations, but not in others (Chilcote, 2003; Sharma et al., 2006; Araki et al., 2007a, b).

\section{(c) Genetic consequences}

Direct genetic interactions may result in introgression, the level of which is strongly influenced by the relative abundance and fitness of the natural and cultured stocks and their hybrids, and the degree to which the two populations are reproductively separated by behavioural differences etc. Introgression rates will be largest when both populations are of the same fitness and recent ancestry, and decline with increasing fitness and ancestral difference. Outbreeding depression, where hybrids are less fit than either parent population, may reduce introgression as compared to the more common situation where hybrids are of intermediate fitness (Reisenbichler \& Rubin, 1999; Reisenbichler et al., 2003). Introgression can affect genetic diversity, structure and fitness of populations. To assess consequences of introgression, we need to consider the genetic characteristics of the wild and cultured populations, and the quantitative level of interaction [see Ryman \& Laikre (1991), Ford (2002) and Goodman (2005) for quantitative assessments of diversity and fitness consequences of introgression].

Cultured populations often harbour lower levels of genetic diversity than wild populations, due to low effective population size (tens, or at the most a few hundreds) and its effects on genetic drift and inbreeding. Introgression of cultured into wild populations can be associated with a 
loss of genetic diversity in the resulting, mixed population (Ryman \& Laikre, 1991). The risk of loss of diversity is greatest when fish of cultured origin contribute substantially to the mixed population, but have a much lower effective population size than the wild population. This situation can arise relatively easily because high fecundity of fish combined with high survival of early life stages in culture makes it possible to produce very large numbers of offspring from very few parents. Loss of genetic diversity reduces the ability of the population to respond to environmental change (Hilborn et al., 2003; Reed \& Frankham, 2003). In wild populations that are very small, the opposite situation may occur: cultured populations may be of greater effective size and introgression can increase diversity in the wild population. This may be helped by factorial mating designs that can increase effective population size to about twice the census size. In addition, culture systems offer some protection from demographic stochasticity and the possibility of rapid population expansion, both opportunities for conserving genetic diversity in populations that are already small and endangered (Hedrick et al., 2000).

Wild fish populations show spatial structure in selectively neutral markers where isolation has been sufficiently strong and long-term, and adaptive genetic variation that may be maintained by natural selection even at more moderate levels of isolation (Utter, 2004; Conover et al., 2006). Freshwater fish species show far greater differentiation in neutral markers than marine species, with anadromous species occupying an intermediate position (Ward, Woodwark \& Skibinski, 1994). However, adaptive genetic variation has been found at relatively small spatial scales in freshwater, anadromous and even marine species (Reisenbichler, 1988; Conover et al., 2006; Mehner et al., 2009). Local adaptations of life-history traits appear to be widespread, maintained and dynamically remoulded by the continuous action of selection and migration.

Where cultured fish are derived from a local brood stock and released over a large geographical area or vice versa, the consequence of introgression is a loss of spatial genetic differentiation and in particular, local adaptations in the wild population (Araguas et al., 2004; Mehner et al., 2009). Such effects can be reduced by taking account of wild population genetic structure in the founding of brood stock and the movement of cultured offspring prior to (accidental or deliberate) release. However, in practice it may be difficult to establish this structure and emulate it in culture (Utter \& Epifanio, 2002; Miller \& Kapuscinski, 2003). Where the cultured population is of lower fitness than the wild population (due to domestication effects and/or lack of local adaptation), introgression will reduce fitness of the combined, naturally recruited population relative to a mixture without introgression. The level of introgression itself is dependent on the relative fitness and the relative abundance of the population components. Cultured fish of very low fitness are unlikely to achieve much introgression unless their relative abundance is very high. Both relative fitness and relative abundance must be considered in risk assessments and it is important to bear in mind that cultured fish with only moderately compromised fitness in the wild can have greater effects on the fitness of the naturally recruiting population component than those that are very unfit (Lorenzen, 2005). Particularly deleterious outcomes may be expected for trait combinations that increase introgression in the short term, which will have negative consequences for long-term fitness (Muir \& Howard, 2002; Garant et al., 2003).

Overall, it appears that poor fitness of cultured fish in the wild has often limited both the success of deliberate releases and deleterious ecological and genetic interactions, except in cases where releases of unfit cultured fish are numerically very large. Adoption of culture methods that increase performance in the wild will make ecological interactions more widespread and severe, even if direct genetic interactions are well managed. Strong ecological (and therefore, indirect genetic) interactions to the extent of direct replacement of the wild stock component are evident in enhanced fisheries where cultured fish perform reasonably well in the wild (Hilborn \& Eggers, 2000).

\section{(3) Interspecific interactions}

Interspecific biological interactions can arise where cultured fish increase the abundance of existing wild populations or establish new populations where the species was previously absent. In either case, the strongest impacts on other fish species are likely to arise due to predation from stocked piscivores, or due to biogenic habitat modification by stocked species that may, for example, reduce macrophyte abundance or increase turbidity (Welcomme, 1988, Beveridge, Ross \& Kelly, 1994; FAO, 1999; Eby et al., 2006). Interspecific competitive interactions tend to be weaker, but may also be significant (e.g. Levin \& Williams, 2002). The fact that the released cultured fish have been modified from their wild type through a process of domestication may be less important in interspecific than in intraspecific interactions. It is likely, though, that the comparatively low post-release fitness of cultured fish also reduces their likelihood of establishment and possibly, severity of impact compared to introductions of wild fish of the same species.

Impacts of escaped or stocked non-native species are widely perceived as a more serious threat to native biota than the release of native species. However, this perception must be qualified. Non-native fishes undoubtedly have contributed to threats and extinctions of native fishes, and many of the former have originated from culture operations (Welcomme, 1988). On the other hand the majority of non-native fishes have integrated into existing communities without causing extinctions or even drastic changes in the abundance of native species (Moyle \& Light, 1996; Williamson, 1996; Gozlan, 2008; Arthur et al., 2010). The strongest effects on native fishes are typically associated with non-native predators (Moyle \& Light, 1996; Ruesink, 2005; Eby et al., 2006). Direct and indirect competitive interactions have also been implicated in some local extinctions (Harig, Fausch \& Young, 2000; Townsend, 2003). Hybridization between closely related cultured and wild species has been shown to occur 
and can contribute to loss of genetic integrity and/or fitness of the wild population (Hitt et al., 2003). Both competitive interactions and hybridization may be particularly prevalent where the cultured and wild species are closely related.

\section{(4) Disease interactions}

Impacts on wild stocks from disease interactions may occur via three mechanisms: (1) introductions of alien pathogens, (2) transfer of pathogens that have evolved increased virulence in culture, (3) changes in host population density, age/size structure or immune status that affect the dynamics of established pathogens. All three impacts can occur when cultured fish are released, or maintained in environmentally open systems such as net cages which allow transmission even when the farmed population is contained.

Introductions of alien pathogens are associated with the most dramatic disease impacts of cultured on wild fish so far documented (Johnsen \& Jensen, 1991; Wagner, 2002; Johansen et al., 2011). Introduction of a pathogen in itself, however, does not necessarily have a great effect unless a sufficiently dense, susceptible recipient population is present (Anderson, 1981). In the case of parasites with indirect life cycles, even more complex ecological conditions must be met for the parasites to establish and impact on host populations. Not surprisingly, the impacts of parasite introductions are highly variable depending on ecological conditions and even wide-ranging transfers can have low impacts where ecological conditions prevent establishment (Kennedy, Hartvigsen \& Halvorsen, 1991; Schisler \& Bergersen, 2002).

Transfer from cultured to wild fish of parasite strains that have evolved increased virulence in culture is a widely held concern (Pulkkinen et al., 2010; Kurath \& Winton, 2011). While transmission may occur directly from cultured to wild individuals where culture systems are environmentally open, it is unlikely that highly virulent strains can invade and persist within low-density wild populations alone (Kurath \& Winton, 2011).

Changes in host population density, age/size structure or immune status of interacting cultured and wild fish population components have been shown to affect transmission dynamics and prevalence of parasites, particularly in cases where overall changes in host density have been large. This is most well documented for the case of sea lice (principlally Lepeophtheirus salmonis and Caligus clemensi) parasitizing wild and pen-cultured salmon (Butler, 2002; Krkošek et al., 2006). Also, high stocking densities of chinook salmon (Oncorhynchus tshareytscha) in Lake Michigan are believed to have contributed to increased prevalence of bacterial kidney disease, with occasional epidemics causing high mortalities (Jude \& Leach, 1999).

Controlling parasites in cultured fish is crucial to minimizing disease interactions with wild fish, but is not always effective and may not be sufficient, particularly where parasite transmission from wild to cultured fish is difficult to eliminate. It is therefore important to implement an epidemiological, risk-based approach to managing disease interactions that accounts for ecological and evolutionary dynamcis of transmission and host population impatcs (Butler, 2002; Bartley, Bondad-Reantaso \& Subasinghe, 2006; Murray \& Peeler, 2005).

\section{(5) Technical interactions}

Technical interactions, which may be intra- or interspecific, arise when the aquaculture or harvesting operations for cultured fish affect wild populations. This may occur through broodstock capture, environmental impacts of culture facilities, or changes in fishing pressure. Broodstock capture can have significant impacts when wild populations are small, which is typically the case in captive breeding programmes for conservation. In larger populations, changes in fishing pressure associated with large-scale release programmes are the most common technical interactions. Pacific salmon (Oncorhynchus spp.) enhancements may have increased fishing pressure on mixed wild-hatchery stocks, though the impact of this on wild stocks remains controversial (Hilborn \& Eggers, 2000). Conversely, harvest restrictions brought in to protect stocked cultured fish may also reduce pressure on wild stocks (Lorenzen et al., 1998; Lorenzen, 2008b). These examples, while not exhaustive, show that technical interactions can be significant and should be considered as part of any cultured-wild fish interaction study.

\section{INTEGRATED MANAGEMENT OF FISH GULTURE AND GULTURED-WILD FISH INTERACTIONS: A TYPOLOGY OF SYSTEMS}

Integrative management combining specific practices in both the culture and the natural system holds great promise for improving outcomes of fish culture and interactions between cultured and wild fish. Different combinations of practices are required for different purposes of fish culture. We identify six management systems (Table 1): (1) commodity aquaculture, (2) culture-based fisheries, ranching and bio-manipulation, (3) fisheries stock enhancement, (4) restocking or stock rebuilding, (5) supplementation and captive breeding, and (6) re-introduction and translocation. These categories represent a continuum from primarily production-oriented systems where the aim is to minimize detrimental impacts on wild populations, to conservation-oriented systems where the aim is to maximise positive impacts. Our typology builds upon and aims to unify typologies of fish culture and use of cultured fish in natural ecosystems developed by Cowx (1994) for stocking in fisheries management, Utter \& Epifanio (2002) for genetics of cultured-wild fish interactions, Naish et al. (2008) for salmonid hatchery programmes, and Lorenzen (2008b) for fisheries enhancements.

Certain aspects of managing culture and cultured-wild fish interactions apply uniformly across management systems while others are differentiated. Among the uniform aspects are general practices of good husbandry in culture such as maintaining good environmental conditions including water quality, and controlling infectious diseases. In the following 


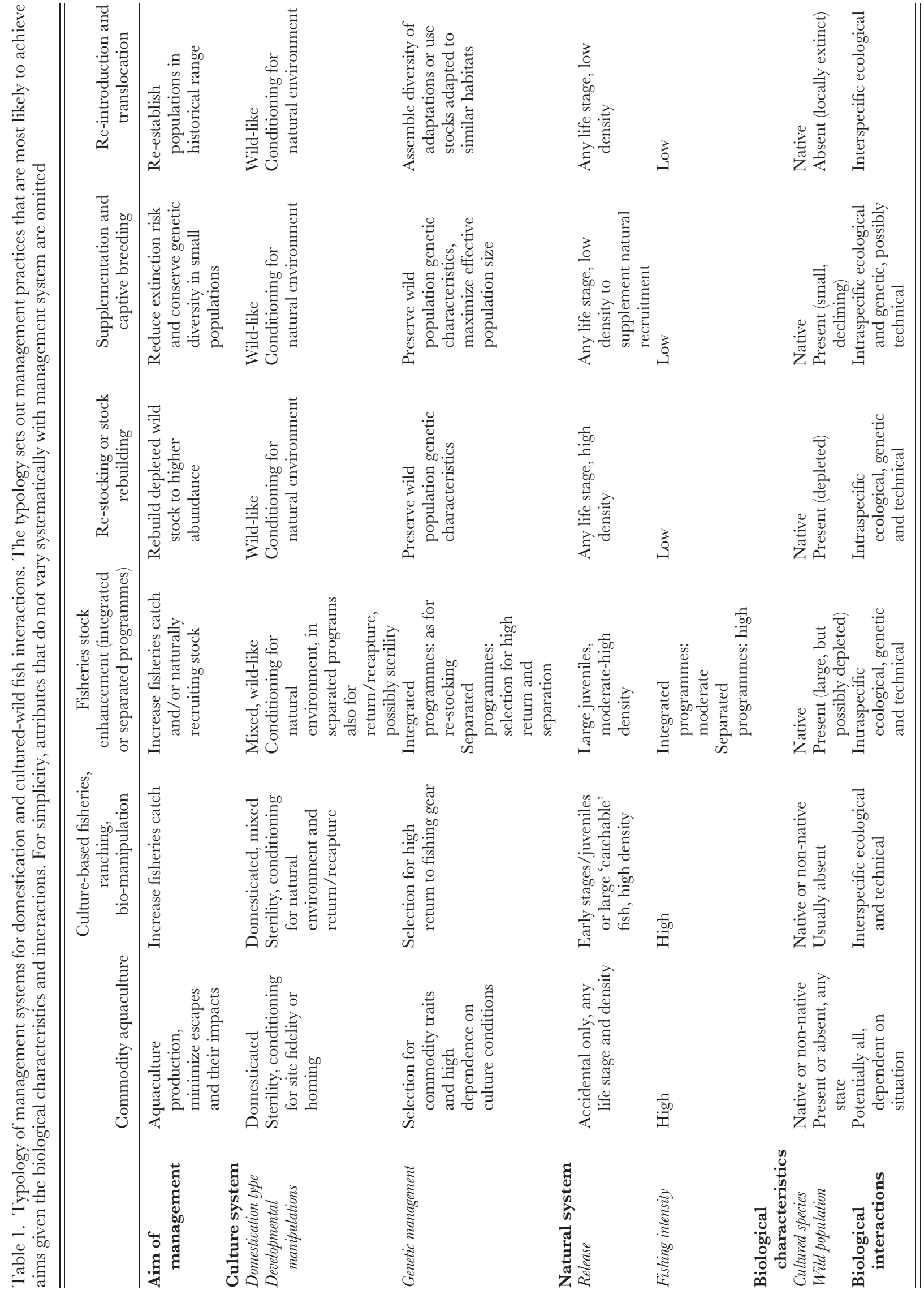


we set out combinations of differentiated management appropriate to different purposes and systems.

\section{(1) Commodity aquaculture}

Commodity aquaculture in confined systems such as tanks, ponds or net pens accounts for the largest share of cultured fish production. Commodity aquaculture benefits from inadvertent and advanced domestication. Escapes generally occur inadvertently (incidences of vandalism, however, do occur in aquaculture) and can involve native or nonnative species, at any stage in the life cycle. Consequently, interactions with wild fish may be dominated by inter- or intraspecific, ecological or genetic interactions depending on the specific attributes of the farming operation. There are two principal means for minimising interactions between cultured and wild fish and their impact on wild populations: (1) minimising escapes through effective containment of cultured fish and recovery of escapees, and (2) minimising impacts of escaped fish through development of genetic manipulations of cultured fish.

Clearly the most effective control strategy is to minimize escapes in the first place. Increased containment in culture facilities is desirable, but may be difficult to achieve in pond and cage systems that are likely to remain the mainstay of commodity aquaculture (Beveridge, 2004). Typical average escape figures for cultured fish are in the order of $2-5 \%$ of stock per year (Beveridge, 2004; Naylor et al., 2004). This may seem very little, but for the most widely cultured species in which cultured populations may exceed the abundance of wild stocks by a factor of ten to fifty (Walker et al., 2006), annual escapes can match or even exceed the abundance of wild stocks. Siting of farms to reduce the risk of flooding and breach of containment structures will have some impact, but an integrated approach to the problem, which adopts a procedure similar to the Hazard Analysis and Critical Control Point (HACCP) approach used in the food industry, is likely to pay greatest dividends. Such an approach would identify the causes of escapes and help focus attention on the areas that require most effort to reduce the incidence of escapes. The use of gear fit for purpose, staff training, the adoption and auditing of industry Codes of Practice as well as the development and implementation of contingency plans all have an important role to play. Recovery measures may be adopted after major escapes, and it may also be possible to promote return or limit straying by manipulating site cues or conditioning the fish (Soto, Jara \& Moreno, 2001; Youngson et al., 2001). Some countries have encouraged or legislated the development of integrated strategies to reduce escapement, with good results (Beveridge, 2004; Naylor et al., 2004; Walker et al., 2006).

In terms of the domestication process, two radically different approaches may be adopted to minimize ecological and genetic impacts of escapees: (1) producing cultured fish that are as similar as possible in their genetic makeup to wild fish so as to minimize deleterious impacts of genetic introgression, or (2) producing fish that are highly dependent on culture conditions and survive poorly in the wild to minimize both ecological impacts and the level of introgression. The first approach may seem intuitively attractive, but maintaining the genetic makeup of wild populations in captivity is inherently difficult (if not well-nigh impossible) and implies foregoing positive contributions to aquaculture from domestication. In addition, wild-like types are likely to show stronger ecological interactions with wild fish than the captive or domesticated types used at present. The second option, increasing dependence of cultured fish on human support, is fully compatible with production efficiency in aquaculture and will reduce both ecological and genetic interactions with wild fish. Dependence on human protection and thus poor performance in the wild is likely to be based on multiple traits (Gepts, 2002; Price, 2002). Selection indices that combine multiple traits, weighted by their utility, into an aggregate breeding value have long been applied in the domestication of higher vertebrates, and will undoubtedly become more widely used in fish (Hazel, Dickerson \& Freeman, 1994; Olesen, Groen \& Gjerde, 2000). Incorporating in the selection index traits that reduce performance in the wild, or an empirical measure of performance in the wild as a trait in its own right, would allow deliberate selection for low impact upon escape. So far, this aspect has received insufficient attention in fish domestication programmes. However, the high level of developmental plasticity and capacity for feralization in fishes, and magnitude of releases imply that measures focusing on the organism alone may not be sufficient. Manipulations that induce sterility eliminate direct genetic interactions of escaped with wild fish. A combined strategy of advancing domestication (thus reducing fitness in the wild) and inducing sterility thus seems the most promising strategy to minimize interactions with wild fish.

Commodity aquaculture has been associated with introductions of non-native species, some of which have become invasive (Naylor, Williams \& Strong, 2001). However, other non-indigenous species are known not to establish feral populations or to interact only mildly with native fish even if they do establish. Examples include riverine major carps released into lakes and reservoirs in Asia or Atlantic salmon escapees from aquaculture facilities in the Pacific (Soto et al., 2001; Cubitt et al., 2006; Arthur et al., 2010). Culturing such nonnative species may have less impact on native populations than culturing of native species where the latter are partially domesticated and poorly contained.

\section{(2) Culture-based fisheries, ranching, bio-manipulation}

In culture-based fisheries or ranching systems, cultured fish are released into natural or semi-natural ecosystems for fish production, creation of recreational fisheries, or biomanipulation (Table 1). Culture-based fisheries or ranching systems usually operate for species that do not reproduce naturally in the target habitat, or where the stocked and natural populations are separated reproductively and ecologically. Some culture-based fisheries and ranching systems use species that are non-native to the region. Interactions with wild fish are 
therefore primarily interspecific and ecological or technical in nature. This form of management probably accounts for the largest share of intentional releases into the wild, from largescale production-oriented reservoir culture-fisheries in Asia to 'put and take' recreational fisheries (Welcomme \& Bartley, 1998; Arlinghaus, Mehner \& Cowx, 2002). The culturebased fishery or ranching system itself is typically stocked and harvested intensively, resulting in a population structure that maximises somatic production and/or the abundance of catchable-sized fish. Such populations are characterized by narrow age and size structure, are virtually devoid of mature fish, and therefore could not be sustained by natural recruitment (Lorenzen, 1995, 2005). Stocking and harvesting patterns in themselves thus limit the potential for the population to become established and self-recruiting. In the case of biomanipulation applications, fishing pressure on released fish may be minimised in order to achieve a high abundance of large fish for effective predation or vegetation control.

Sterile fish may be used in culture-based fisheries and ranching systems where reproduction in the natural ecosystem is possible but undesirable, in particular where non-native species with potentially large ecological impacts are used (e.g. triploid grass carp Ctenopharyngodon idella for vegetation control; Cassani, 1995). Interspecific hybrids may also be used (Bartley et al., 2001). Developmental manipulations such as life-skills training or conditioning may improve post-release performance (Section III.3.c).

Development of locally adapted brood stock is likely to be beneficial and experiments show that there is potential for genetic improvement to benefit culture-based fisheries and ranching systems (Jonasson et al., 1997; Araki et al., 2008). In the absence of direct genetic interactions with wild stocks, post-release fitness of cultured fish is primarily an economic rather than a conservation issue. Low-cost mass production of captive or domesticated-type fish that survive poorly in the wild but are highly susceptible to capture may be economically optimal in certain cases, particularly in put-and-take recreational fisheries where fish are recaptured quickly. Habitat enhancements and predator control measures may complement culture-based fisheries, particularly in inland waters (Welcomme \& Bartley, 1998).

\section{(3) Fisheries stock enhancement}

Stock enhancement involves the continued release of hatchery fish into a wild population, with the aim of sustaining and improving fisheries in the face of intensive exploitation and/or habitat degradation. Stock enhancement is distinguished from culture-based fisheries and ranching by the presence of a wild population, and from the more conservation-oriented approaches of supplementation and restocking by its primary focus on production (Table 1). Examples of stock enhancements include the Alaska salmon (Oncorhynchus spp.) enhancements and many smaller initiatives, mostly in freshwater environments (Welcomme \& Bartley, 1998; Hilborn \& Eggers, 2000). Under certain conditions, stock enhancements can substantially increase overall abundance of catchable fish and fisheries yield, while allowing for higher exploitation rates than could be sustained by the natural stock alone (Lorenzen, 2005). In doing so, however, enhancements tend to reduce abundance and productivity of the naturally recruiting population component below the levels associated with sustainable exploitation in the absence of enhancement. In addition, there may be introgression of hatchery genotype fish into the self-recruiting population with implications for its genetic structure and fitness. Such interactions can vary in magnitude from a very slight reduction to complete replacement of wild by released cultured fish, depending on stock characteristics and management (Hilborn \& Eggers, 2000; Levin, Zabel \& Williams, 2001; Lorenzen, 2005). Depending on the relative fitness of wild and released cultured fish, such replacement can lead to an overall reduction in productivity but this is not necessarily the case (Chilcote, 2003; Sharma et al., 2006; Araki et al., 2007a). Where the wild stock is fished within sustainable limits, recruitment compensation implies that natural reproduction of released hatchery fish will make at best a small net contribution to natural recruitment, while posing potentially substantial ecological and genetic risks (Lorenzen, 2005). Particular erosion of wild population fitness may occur when the hatchery contribution is large and hatchery and wild fish interact reproductively (Utter, 2004; Goodman, 2005; Lorenzen, 2005). Several modelling tools are now available for quantitatively assessing fisheries benefits and impacts on wild populations from stock enhancements, including the EnhanceFish model for iteroparous species (Lorenzen, 2005; Medley \& Lorenzen, 2006), and the 'All-H Analyzer' for semelparous salmonids (Mobrand, Jones and Stokes Associates, 2006).

Because stock enhancements can depress wild population abundance and fitness through multiple ecological, genetic and technical interactions, it is likely to be advantageous to separate cultured and wild population components as far as technically possible (Utter, 2004; Lorenzen, 2005; Chilcote, Goodson \& Faley, 2011). Releasing hatchery fish as advanced juveniles (thus reducing interactions with wild juveniles at the stage when compensatory density-dependence is particularly strong) and selective harvesting of hatchery fish, possibly combined with manipulations to induce sterility, can greatly reduce ecological and genetic interactions with wild fish (Lorenzen, 2005). Separation of cultured and wild stocks of the same species can also be facilitated by promoting differentiation in spatial distributions through homing or conditioning, and artificial selection for differences in the timing of spawning (Mackey, McLean \& Quinn, 2001; Hayes et al., 2004).

Enhancement programs with effectively separated cultured and wild stocks are likely to offer greater fisheries enhancement potential and reduced impact on wild stocks compared to programs with integrated stocks. So far, effective separation has been achieved only in certain enhancement programs for anadromous salmonids (Mobrand et al., 2005; Naish et al., 2008). Options for achieving separation of cultured and wild stocks should be explored in stock enhancements for other species. 


\section{(4) Restocking or stock rebuilding}

Restocking or stock rebuilding involve temporary releases of hatchery fish aimed at rebuilding depleted populations more quickly than would be achieved by natural recovery. In restocking, release number must be substantial relative to the abundance of the remaining wild stock if rebuilding is to be significantly accelerated. Fishing intensity should be low in order to maximise the contribution of wild and released cultured fish to population growth. Restocking calls for close ecological and genetic integration of wild and cultured stocks, combined with very restricted harvesting. Genetic management is clearly focused on maintaining the characteristics of the wild population, and developmental manipulations likewise may be carried out to produce 'wildlike' fish. Restocking may be considered when population abundance is substantially below carrying capacity as a result of overfishing or environmental catastrophes. It may also be used where habitats have been restored or enhanced so that carrying capacity has expanded but population expansion is slow. Restocking is used widely to restore freshwater fisheries after pollution events, or in conjunction with habitat restoration (Philippart, 1995).

Ecological interactions between released cultured and wild fish are likely to be weak in the early stages of restocking when the wild population is at a small fraction of carrying capacity, but will increase as the population recovers. Theoretical analyses and empirical evidence show that where populations have been depleted by overfishing, a substantial reduction in fishing intensity is always required to achieve stock rebuilding, and restocking is likely to be effective as an additional measure only in very depleted populations (Richards \& Rago, 1999; Lorenzen, 2005). On the other hand, where populations are at a low fraction of carrying capacity due to a catastrophic event and fishing pressure is low, restocking may be the only active management intervention that can boost population recovery.

Empirical evidence of variable natural recovery following fish stock collapses suggests that populations can become 'trapped' in a degraded state (Hutchings, 2001), possibly owing to multiple factors such as ecosystem effects (Walters \& Kitchell, 2001), genetic deterioration (Olsen et al., 2004), and modified intraspecific interactions (see also Caughley, 1994). In principle, restocking programmes could address some of these issues, helping depleted populations to 'break out of the trap' and regain a capacity for increase. This possibility has not been tested, but experimental restocking programmes for such populations could make crucial contributions to the understanding of recovery processes.

\section{(5) Supplementation and captive breeding}

Supplementation is defined here as the continued release of cultured fish into very small and declining populations, with the aim of reducing extinction risk and conserving genetic diversity. Captive breeding (maintaining a brood stock in captivity) is often part of supplementation efforts. Supplementation primarily serves conservation aims, and specifically addresses threat processes in small and declining populations: demographic stochasticity, loss of genetic diversity, and Allee effects (Caughley, 1994). Supplementation has been used most widely in salmonids (Hedrick et al., 2000; Hilderband, 2002).

Supplementation typically involves only moderate releases in order not to depress the wild population component further, stringent restrictions on harvesting, and auxiliary measures such as habitat restoration and control of nonindigenous species. Genetic management is clearly focused on maintaining the structure and adaptations of the wild stock. Interactions between cultured and wild fish in supplementation are broadly similar to those described for stock enhancement, but modified by processes that are germane to the dynamics of small and declining populations. Ecologically, the key process is demographic stochasticity, with the implication that supplementation releases can reduce population extinction risk even where this leads to some replacement of wild with cultured fish (Hildebrand, 2002). Genetically, the key processes are the random loss of alleles in small populations, and inbreeding if the population remains small for extended periods. In supplementation hatcheries, breeding plans can be designed that substantially increase the genetically effective population size compared to that of the same population under random mating (Hedrick et al., 2000; Frankham et al., 2002). Supplementation can thus mitigate against extinction from demographic stochasticity and maintain or expand genetically effective population size, but may carry short and medium-term fitness costs (Fraser, 2008). Programmes that are implemented as short-term interventions to avoid imminent extinction are considered more likely to achieve long-term population viability than approaches that require long-term supplementation and thus, perpetuate fitness costs of hatchery rearing (McClure et al., 2008). Supplementation may also reduce natural recruitment through density-dependent processes and thus increase dependence on continued captive breeding unless available habitat is increased. Also, extinction risk may remain substantial even in supplemented populations, and establishing a captive or translocated stock without supplementing the native population should be considered as an alternative to supplementation. Where the natural population is very small, it may be best to bring the whole population into captivity where mortality rates tend to be much lower than in the wild, and effective population size can be maximised. The best approach (no supplementation, supplementation, establishment of a captive population only, or complete transfer into captivity) will depend on relative magnitude of risks under different scenarios, but these are often difficult to quantify (Tenhumberg et al., 2004).

\section{(6) Re-introduction and translocation}

Re-introduction and translocation involve temporary releases of cultured or captured fish with the aim of reestablishing a locally extinct population. The fish to be released may have been cultured, possibly for multiple generations, or may be brought into captivity only briefly as part 
of a translocation of wild stock. Re-introduction aims to establish a healthy population that is $(i)$ genetically adapted to the local environment, (ii) self-sustaining at abundances consistent with the carrying capacity of the river system, (iii) genetically compatible with neighbouring populations so that substantial outbreeding depression does not result from straying and interbreeding between populations, and (iv) sufficiently diverse genetically to accommodate environmental variability over many decades (Reisenbichler et al., 2003). Re-introduction and translocation are widely used in the restoration of freshwater fish populations (Philippart, 1995).

Interactions between cultured and wild fish in reintroduction and translocation initiatives are temporary and weak, owing to the low numbers of cultured fish normally released. However, successful re-establishment of a wild population may result in significant interspecific ecological interactions. Fish may be released at any life stage, normally in numbers that are relatively small, but large enough to allow establishment and to enable genetic processes to maintain diversity and fitness in the population being reestablished. Fishing pressure should be minimized to allow rapid expansion of the population. A particular issue in reintroduction is the genetic makeup of the founder population to be released. Unless a representative and sufficiently large sample of the original population has been brought into captivity prior to its extinction in the wild, the re-introduced population must be assembled from populations other than that originally present. Reisenbichler et al. (2003) point out that while it is generally best to adhere to the ancestral lineages for the species to be restored, establishment success is likely to be greatest for fish from populations adapted to similar environmental conditions, which may not always be those now extant from the lineage that was originally present in the release habitat. However, mixing genetically divergent sources may lead to outbreeding depression in second-generation fish (Huff et al., 2011). Following initial establishment, releases should be discontinued so as to allow the population to evolve a natural structure and adapt to its new environment (Reisenbichler et al., 2003).

\section{DIRECTIONS FOR IMPROVING MANAGEMENT AND FOR RESEARGH}

\section{(1) Improving management}

We have set out in the introduction and re-emphasize here the case for adopting an integrative approach to the management of cultured fish, within and outside culture facilities. Our framework (Fig. 1), review and typology of management systems (Section V, Table 1) can be used to inform such an approach and guide its implementation. Clear goals should be formulated for fish culture and domestication strategies, bearing in mind that different uses of fish culture call for very different approaches (Section III.2). Assessment and management of cultured-wild fish interactions should integrate across ecological and genetic interactions and account for the impacts of domestication-related fitness declines on both (Section IV.2). An epidemiological, riskbased approach taking into account the ecological and evolutionary dynamics of parasite transmission should be adopted to managing disease interactions (Section IV.4). Lorenzen, Leber \& Blankenship (2010) outline an approach to the development or reform of fisheries enhancements that embodies these principles. A large-scale, systematic application of many of these principles can be found in the Hatchery Reform processes implemented in the Pacific Northwest of the U.S.A. (Mobrand et al., 2005).

\section{(2) Directions for research}

Research on fish domestication and on cultured-wild fish interactions has the potential to generate substantial benefits for aquaculture in the widest sense, for fisheries management, and for the conservation of threatened fish populations. It also provides unique insights into fundamental biological questions.

Perhaps the most important, overarching direction for research is the development of a quantitative evolutionaryecological theory of domestication and of cultured-wild fish interactions. We now have assembled a vast body of empirical knowledge on many facets of fish domestication and cultured-wild fish interactions. However, there has been limited synthesis, integration and theory development. Most theoretical studies on the subject have relied on mathematical models that, while motivated by ecological or evolutionary theory, have been primarily conceptual and disciplinary and have not been confronted with data (e.g. Ford, 2002; Goodman, 2005; Lorenzen, 2005). Development and testing of theoretical models that integrate across disciplines and scales holds the key to further progress: integration of ecological and genetic considerations, over the life cycle, and from individuals to populations.

One core area where this approach is likely to be fruitful is the evolutionary ecology of domestication. Analysing the effects of environmental manipulations and selection on the organism's biology may unravel the mechanisms underlying adaptation: disentangling direct environmental effects on development, reaction norms that have been shaped by natural selection, and genetic constraints (Conner, 2003; Fuller, Baer \& Travis, 2005). Life-history theory offers a conceptual basis for such analyses but has not been systematically applied to domestication issues (Roff, 1992). The second core area of theory development concerns manipulations of wild populations through releases of cultured fish. Fisheries enhancement and conservation hatchery programmes designed as experiments may provide unique insights into the population biology of wild fish stocks (Lorenzen, 2000a; Smith et al., 2002; Nislow, Einum \& Folt, 2004). This could include manipulations to raise the abundance of depleted or declining populations in order to gain insights into processes that may prevent natural recovery and which remain poorly understood (Caughley, 1994; Hutchings, 2001).

Better empirical information is urgently required on how specific domestication interventions (both developmental and 
genetic) affect the performance of cultured fish in natural systems and their interactions with wild fish. This will resolve the question whether, how and when (given responses achievable in selective breeding programmes) advancing domestication will increase dependence on human support and reduce survival in the wild to the extent that interactions of escapees with wild fish become insignificant. The greatest advances in the short term may be achievable by inducing sterility in fish destined for commodity aquaculture and production-oriented fisheries enhancements. Again, better information on the performance of sterile fish in the wild, in particular with respect to possible interference with reproduction in wild fish is urgently required. Long-term experimental research in natural systems is likely to be required to provide the required link between specific domestication effects and performance, but meta-analysis of existing studies should also prove informative.

\section{GONGLUSIONS}

(1) An integrative biological approach: integrating over ecological and evolutionary perspectives, culture and natural systems with associated management practices, and multi-dimensional outcomes provides new insights into domestication issues in fish culture and interactions between cultured and wild fish.

(2) Domestication is a dynamic process. We propose four modes of domestication that lead to alternative sets of cultured "types" (sets of phenotypes and genotypes) of organisms. The first mode of domestication is dominated by inadvertent responses to the culture environment, and leads to the evolution of captive types. Advanced modes of domestication involve targeted manipulations of the organism's biology away from the captive type. This may involve the promotion of commodity traits to produce a range of fully domesticated types, promotion of the wild genotype and phenotype under culture conditions to produce or maintain a range of wild-like types, or promotion of mixed types with a combination of commodity and wild-like traits for culture-based and enhanced fisheries.

(3) Controlled (directed) domestication can yield benefits for all forms of aquaculture, but inadvertent or poorly managed domestication can be detrimental to aquaculture as well as to wild stocks. Many problems casually attributed to domestication of fish are in fact problems of too little, or too muddled domestication. More explicit attention to, and constructive management of, domestication processes is likely to make significant contributions to the sustainable development of aquaculture and the use of culture technologies in conservation of endangered species.

(4) Ecological and genetic interactions between cultured and wild fish are widespread, often significant, and closely linked. Integrated, quantitative assessment of ecological and evolutionary dynamics is required to understand and predict outcomes of interactions. Relevant concepts and models are increasingly available. Critical uncertainties surround the quantitative effects of different domestication strategies on the fitness of cultured fish in the wild.

(5) Integrative management combining specific practices in both the culture and the natural system holds great promise for improving outcomes and fish culture and interactions between cultured and wild fish. Different combinations of practices are required for different purposes of fish culture. We identify six management systems: (1) commodity aquaculture, (2) culture-based fisheries, ranching and biomanipulation, (3) fisheries stock enhancement, (4) restocking or stock rebuilding, (5) supplementation and captive breeding, and (6) re-introduction and translocation.

(6) Research on fish domestication and on cultured-wild fish interactions is likely to generate substantial benefits for aquaculture, fisheries and fish conservation and to provide unique insights into fundamental biological questions. Key directions for research include advancing the quantitative evolutionary-ecological theory of domestication and of cultured-wild fish interactions and empirically assessing impacts of different domestication strategies and specific manipulations on fitness of cultured fish in the wild.

\section{AGKNOWLEDGEMENTS}

The senior author (K.L.) acknowledges support from the Center for Stock Assessment Research (a partnership between the Fisheries Ecology Division, Southwest Fisheries Science Center and UG Santa Cruz), the Florida State University William $\mathrm{R}$ and Lenore Mote Eminent Scholar Chair in Fisheries Ecology, and a Sport Fish Restoration (SFR) grant from the U.S. Fish and Wildlife Service through the Florida Fish and Wildlife Conservation Commission's SFR projects F-135-R and F-136-R. M.B. wishes to acknowledge support from a Visiting Fellowship to Imperial College (2007-2008). The work of M.M. was partially supported by the US National Science Foundation and the Center for Stock Assessment Research. We acknowledge helpful comments on drafts by Lee Blankenship, Curtis Lind, Raul Ponzoni, Colette St. Mary and two anonymous referees.

\section{REFERENGES}

\footnotetext{
Allendorf, F. W., Ryman, N. \& Utter, F. (1987). Genetic management of hatchery stocks. In Population Genetics and Fisheries Management (eds N. RyMAn and F. UTTER), pp. 11 -19. University of Washington Press, Seattle.

Anderson, R. M. (1981). Population ecology of infectious disease agents. In Theoretical Ecology (ed. R. M. MAY), pp. 318-355. Blackwell, Oxford.

Araguas, R. M., Sanz, N., Pla, C. \& Garcia-Martin, J. L. (2004). Breakdown of the brown trout evolutionary history due to hybridization between native and cultivated fish. Fournal of Fish Biology 65 (Suppl. A), 28-37.

Araki, H., Ardren, W. R., Olsen, E., Coper, B. \& Blouin, M. S. (2007a). Reproductive success of captive-bred steelhead trout in the wild: evaluation of three hatchery programs in the hood river. Conservation Biology 21, 181-190.

Araki, H., Cooper, B. \& Blouin, M. S. (2007b). Genetic effects of captive breeding cause a rapid, cumulative fitness decline in the wild. Science 318, 100-103.

Araki, H., Berejikian, B. A., Ford, M. J. \& Blouin, M. S. (2008). Fitness of hatchery-reared salmonids in the wild. Evolutionary Applications 1, 342-355.

Araki, H., Cooper, B. \& Blouin, M. S. (2010). Carry-over effect of captive breeding reduces reproductive fitness of wild-born descendants in the wild. Biology Letters $\mathbf{5}$ $621-624$
} 
Araki, H. \& Schmid, C. (2010). Is hatchery stocking a help or a harm? Evidence, limitations and future directions in ecological and genetic surveys. Aquaculture 308 (Suppl. 1), S1-S11.

Arlinghaus, R., Mehner, T. \& Cowx, I. G. (2002). Reconciling traditional inland fisheries management and sustainability in industrialized countries, with emphasis on Europe. Fish and Fisheries 3, 261-316.

Arthur, R. I., Lorenzen, K., Homekingkeo, P., Sidavong, K., SanviLAIKHAM, B. \& Garaway, C. J. (2010). Assessing impact of introduced aquaculture species on native fish communities: Nile tilapia and major carps in SE Asian freshwaters. Aquaculture 299, 81-88.

Ashley, P. J. (2007). Fish welfare: current issues in aquaculture. Applied Animal Behaviour Science 104, 199-235.

Balon, E. K. (2004). About the oldest domesticates among the fishes. Fournal of Fish Biology 65 (Suppl. 1), 1-27.

Bartley, D. M., Bondad-Reantaso, M. G. \& Subasinghe, R. P. (2006). A risk analysis framework for aquatic animal health management in marine stock enhancement programmes. Fisheries Research 80, 28-36.

Bartley, D. M., Kent, D. M. \& Drawbridge, M. A. (1995). Conservation of genetic diversity in a white bass hatchery enhancement program in southern California. American Fisheries Society Symposium 15, 249-260.

Bartley, D. M., Rana, K. \& Immink, A. J. (2001). The use of inter-specific hybrids in aquaculture and fisheries. Reviewes in Fish Biology and Fisheries 10, 325-337.

Beilharz, R. G., Luxford, B. G. \& Wilkinson, J. L. (1993). Quantitative genetics and evolution - is our understanding of genetics sufficient to explain evolution? Journal of Animal Breeding and Genetics 110, 161-170.

Berejikian, B. A., Tezak, P. E., Flagg, T. A., LaRea, A. L., Kummerow, E. \& Mahnken, C. V. W. (2000). Social dominance, growth, and habitat use in age-0 steelhead (Oncorhynchus mykiss) grown in enriched and conventional hatchery rearing environments. Canadian Journal of Fisheries and Aquatic Sciences 57, 628-636.

Beveridge, M. C. M. (2004). Cage Aquaculture. Fourth Edition. Blackwell Publishing, Oxford.

Beveridge, M. C. M., Ross, L. G. \& Kelly, L. A. (1994). Aquaculture and biodiversity. Ambio 23, 497-502.

Bilio, M. (2008). Controlled Reproduction and Domestication in Aquaculture. European Aquaculture Society, Oostende.

Bostock, J., McAndrew, B., Richards, R., Jauncey, K., Telfer, T., Lorenzen, K., Little, D., Ross, L., Handisyde, N. \& Gatward, I. (2010). Aquaculture: global status and trends. Philosophical Transactions of the Royal Society B 365, 2897-2912.

Braithwaite, V. A. \& Salvanes, A. G. V. (2005). Environmental variability in the early rearing environment generates behaviourally flexible cod: implications for rehabilitating wild populations. Proceedings of the Royal Society B 272, 1107-1113.

Bromage, N. (1995). Broodstock management and seed quality-general considerations. In Broodstock Management and Egg and Larval Quality (eds R. J. RoBERTS and N. Bromage), pp. 1-24. Blackwell Science, Oxford.

Brown, C. \& DAY, R. L. (2002). The future of enhancements: lessons for hatchery practice from conservation biology. Fish \& Fisheries 3, 79-94.

Brown, C. \& LALAND, K. L. (2001). Social learning and life skills training in hatchery reared fish. Journal of Fish Biology 59, 471-493.

ButLer, J. R. A. (2002). Wild salmonids and sea louse infestations on the west coast of Scotland: sources of infection and implications for the management of marine salmon farms. Pest Management Science 58, 595-608.

Cassani, J. R. (1995). Problems and prospects for grass carp as a management tool. American Fisheries Society Symposium 15, 407-412.

Caughley, G. (1994). Directions in conservation biology. Foumal of Animal Ecology 63, $215-244$.

Chao, N. H. \& Liao, I. C. (2001). Cryopreservation of finfish and shellfish gametes and embryos. Aquaculture 197, 161-189.

Chilcote, M. W. (2003). Relationship between natural productivity and the frequency of wild fish in mixed spawning populations of wild and hatchery steelhead (Oncorhynchus mykiss). Canadian Fournal of Fisheries and Aquatic Sciences 60, 1057-1067.

Chilcote, M. W., Goodson, K. W. \& Faley, M. R. (2011). Reduced recruitment performance in natural populations of anadromous salmonids associated with hatchery-reared fish. Canadian fournal of Fisheries and Aquatic Sciences 68, 511-522.

Cipriano, R. G., Marchant, D., Jones, T. E. \& Schachte, J. H. (2002). Practical application of disease resistance: a brook trout fishery selected for resistance to furunculosis. Aquaculture 206, 1-17.

Clutton-Brock, J. (1987). A Natural History of Domesticated Mammals. Cambridge University Press, Cambridge.

Conover, D. O. (1998). Local adaptation in marine fishes: evidence and implications for stock enhancement. Bulletin of Marine Science 62, 477-493.

Conner, J. K. (2003). Artificial selection: a powerful tool for ecologists. Ecology 84, $1650-1660$.

Conover, D. O., Clarke, L. M., Munch, S. B. \& Wagner, G. N. (2006). Spatial and temporal scales of adaptive divergence in marine fishes and the implications for conservation. Fournal of Fish Biology 69, 21-47.

Cowx, I. G. (1994). Stocking strategies. Fisheries Management and Ecology 1, 15-31.
Cubitt, K. F., Butterworth, K. G., Finstad, B., Huntingford, F. \& McKinley, R. S. (2006). Escaped Farmed Salmon; A Threat to BC's Wild Salmon? Fraser Institute Alert Series. Fraser Institute, Vancouver.

Devlin, R. H., Biagi, C. A., Yesaki, T. Y., Smailus, D. E. \& Byatt, J. C. (2001). Growth of domesticated transgenic fish. Nature 409, 781-782.

Duarte, C. M., Marba, N. \& Holmer, M. (2007). Rapid domestication of marine species. Science 316, 382-383.

Dunham, R. A. (1990). Production and use of monosex or sterile fishes in aquaculture. Revieres in Aquatic Sciences 2, 1-17.

Dunham, R. A., Majumdar, K., Hallerman, E., Bartley, D., Mair, G., Hulata, G., Liu, Z., Pongthana, N., Bakos, J., Penman, D., Gupta, M., Rothlisberg, P. \& Hoerstgen-Schwark, G. (2001). Review of the status of aquaculture genetics. In Aquaculture in the Third Millennium (eds R. P. Subasinghe, P. Bueno, M. J. Phillips, C. Hugh and S. E. McGladdery), pp. 137-165. FAO, Rome.

Eby, L. A., Roach, J. W., Crowder, L. A. \& Stanford, J. A. (2006). Effects of stocking-up freshwater food webs. Trends in Ecology and Evolution 21, 576-584.

ERSBAK, K. \& HAASE, B. L. (1983). Nutritional deprivation after stocking as a possible mechanism leading to mortality in stream-stocked brook trout. North American Fournal of Fisheries Management 3, 142-151.

FAirchild, E. A. \& Howell, W. H. (2004). Factors affecting the post-release survival of cultured juvenile Pseudopleuronectes americanus. Fournal of Fish Biology 65 (Suppl. A), $69-78$.

Fao (1999). Global Characterisation of Inland Fisheries Enhancements and Associated Environmental Impacts, FAO Fisheries Circular 945. Food and Agriculture Organization of the United Nations, Rome.

Fiumera, A. C., Porter, B. A., Looney, G., Asmussen, M. A. \& Avise, J. C. (2004). Maximising offspring production while maintaining genetic diversity in supplemental breeding programs of highly fecund managed species. Conservation Biology 18, 94-101.

Fleming, I. A. \& Petersson, E. (2001). The ability of released, hatchery salmonids to breed and contribute to the natural productivity of wild populations. Nordic fournal of Freshwater Research 75, 71-98.

Ford, M. J. (2002). Selection in captivity during supportive breeding may reduce fitness in the wild. Conservation Biology 16, 815-825.

Frankham, R. (1995). Effective population-size adult-population size ratios in wildlife - a review. Genetical Research 66, 95-107.

Frankham, R. (2008). Genetic adaptation to captivity in species conservation programs. Molecular Ecology 17, 325-333.

Frankham, R., Ballou, J. D. \& Briscoe, D. A. (2002). Introduction to Conservation Genetics. Cambridge University Press, Cambridge.

Frankham, R., Manning, H., Margan, S. H. \& Briscoe, D. A. (2000). Does equalization of family size reduce genetic adaptation to captivity? Animal Conservation $3,357-363$.

FraSER, D. J. (2008). How well can captive breeding programs conserve biodiversity? A review of salmonids. Evolutionary Applications 1, 535-586.

Fuller, R. C., Baer, C. F. \& Travis, J. (2005). How and when selection experiment might actually be useful. Integrative and Comparative Biology 45, 391-404.

Fuss, H. \& Byrne, J. (2002). Differences in survival and physiology between coho salmon reared in seminatural and conventional Ponds. North American Fournal of Aquaculture 64, 267-277.

Garant, D., Fleming, I. A., Einum, S. \& Bernatchez, L. (2003). Alternative male life-history tactics as potential vehicles for speeding introgression of farm salmon traits into wild populations. Ecology Letters 6, 541-549.

GEPTS, P. (2002). A comparison between crop domestication, classical plant breeding and genetic engineering. Crop Science 42, 1780-1790.

GePts, P. \& PAPA, R. (2002). Evolution during domestication. Encyclopedia of Life Sciences. Available at www.els.net. Accessed 18 March 2009.

Goodman, D. (2005). Selection equilibrium for hatchery and wild spawning fitness in integrated breeding programs. Canadian Fournal of Fisheries and Aquatic Sciences 62, 374-389.

GozLAN, R. E. (2008). Introduction of non-native freshwater fish: is it all bad? Fish and Fisheries 9, 106-115.

Gross, M. R. (1998). One species with two biologies: Atlantic salmon (Salmo salar) in the wild and in aquaculture. Canadian Fournal of Fisheries and Aquatic Sciences 55 (Suppl. 1), $131-144$.

Hammer, K. (1984). Das Domestikationssyndrom. Kulturpflanze 32, 11-34.

Harig, A. L., Fausch, K. D. \& Young, M. K. (2000). Factors influencing success of greenback cutthroat trout translocations. North American fournal of Fisheries Management 20, 994-1004.

Hayes, S. A., Bond, M. H., Hanson, C. V. \& MacFarlane, R. B. (2004). Interactions between endangered wild and hatchery salmonids: can the pitfalls of artificial propagation be avoided in small coastal streams? Journal of Fish Biology 65 (Suppl. S1), 101-121.

Hazel, L. N., Dickerson, G. E. \& Freeman, A. E. (1994). The selection index - then, now, and for the future. Fournal of Dairy Science 77, 3236-5251.

Hedrick, P. W., Hedgecock, D., Hamelberg, S. \& Croci, S. J. (2000). The impact of supplementation in winter-run chinook salmon on effective population size. The fournal of Heredity $\mathbf{9 1}, 112-116$. 
Hilborn, R. \& EgGers, D. (2000). A review of the hatchery programs for pink salmon in Prince William Sound and Kodiak Island, Alaska. Transactions of the American Fisheries Society 129, 333-350.

Hilborn, R., Quinn, T. P., Schindler, D. E. \& Rogers, D. E. (2003). Biocomplexity and fisheries sustainability. Proceedings of the National Academy of Sciences 100, 6564-6568.

Hilderbrand, R. H. (2002). Simulating supplementation strategies for restoring and maintaining stream resident cutthroat trout populations. North American Fournal of Fisheries Management 22, 879-887.

Hindar, K., Fleming, I. A., McGinnity, P. \& Diserud, O. (2006). Genetic and ecological effects of salmon farming on wild salmon: modelling from experimental results. ICES Journal of Marine Science 63, 1234-1247.

Hitt, N. P., Frissell, G. A., Muhlfeld, C. C. \& Allendorf, F. W. (2003). Spread of hybridization between native westslope cutthroat trout, Oncorhynchus clarki lewisi, and nonnative rainbow trout, Oncorhynchus mykiss. Canadian Fournal of Fisheries and Aquatic Sciences 60, 1440-1461.

Huff, D. D., Miller, L. M., Chizinski, G. J. \& Vondracek, B. (2011). Mixedsource reintroductions lead to outbreeding depression in second-generation descendents of a native North American fish. Molecular Ecology 20, 4246-4258.

Hulata, G. (2002). Genetic manipulations in aquaculture: a review of stock improvement by classical and modern technologies. Genetica 111, 155-173.

HuNTINGFORD, F. A. (2004). Implications of domestication and rearing conditions for the behaviour of cultivated fishes. Fournal of Fish Biology 65 (Suppl. S1), 122-142.

Hutchings, J. A. (2001). Influence of population decline, fishing and spawner variability on the recovery of marine fishes. Fournal of Fish Biology 59 (Suppl. A), $306-322$

Hutchings, J. A. \& Fraser, D. J. (2008). The nature of fisheries- and farminginduced evolution. Molecular Ecology 17, 294-313.

Johnsen, B. O. \& Jensen, A. J. (1991). The Gyrodactylus story in Norway. Aquaculture 98, 289-302.

Johansen, L. H., Jensen, I., Mikkelsen, H., BJørn, P.-A., Jansen, P. A. \& Bergh, Ø. (2011). Disease interaction and pathogens exchange between wild and farmed fish populations with special reference to Norway. Aquaculture 315, 167-186.

JonAsson, J., GJEDRE, B. \& GJEDREM, T. (1997). Genetic parameters for return rate and body weight in sea-ranched Atlantic salmon. Aquaculture 154, 219-231.

Jonsson, B. \& Jonsson, N. (2006). Cultured Atlantic salmon in nature: a review of their ecology and interaction with wild fish. ICES Journal of Marine Science 63, $1162-1181$.

Jude, D. J. \& Leach, J. (1999). Great Lakes fisheries. In Inland Fisheries Management in North America (eds C. A. Kohler and W. A. Hubert), pp. 623-664. American Fisheries Society, Bethesda.

Kapuscinski, A. R., Hayes, K. R., Li, S. \& Dana, G. (2007). Environmental Risk Assessment of Genetically Modified Organisms, Vol. 3: Methodologies for Transgenic Fish. CABI Publishing, Wallingford.

Keller, E. T. \& Murtha, J. M. (2004). The use of mature zebrafish (Danio rerio) as a model for human aging and disease. Comparative Biochemistry and Physiology Part C: Toxicology \& Pharmacology 138, 335-341.

Kennedy, C. R., Hartvigsen, R. \& Halvorsen, O. (1991). The importance of fish stocking in the dissemination of parasites throughout a group of reservoirs. Fournal of Fish Biology 38, 541-552.

Khaw, H. L., Bovenhuis, H., Ponzoni, R. W., Rezk, M. A., Charo-Karisa, H. \& Komen, H. (2009). Genetic analysis of Nile tilapia (Oreochromis niloticus) selection line reared in two environments. Aquaculture 294, 37-42.

Kincaid, H. L. (1995). An evaluation of inbreeding and effective population size in salmonid broodstocks in federal and sate hatcheries. American Fisheries Society Symposium 15, 193-204.

Krkošek, M., Lewis, M. A., Morton, A., Frazer, N. \& Volpe, J. P. (2006). Epizootics of wild fish induced by farm fish. Proceedings of the National Academy of Sciences of the United States of America 103, 15506-15510.

Kurath, G. \& Winton, J. (2011). Complex dynamics at the interface between wild and domestic viruses in finfish. Current Opinion in Virology 1, 1-8.

Laikre, L., Schwartz, M. K., Waples, R., Ryman, N. \& The GeM Working Group (2010). Compromising genetic diversity in the wild: unmonitored large-scale release of plants and animals. Trends in Ecology and Evolution 26, 520-529.

Levin, P. S. \& Williams, J. G. (2002). Interspecific effects of artificially propagated fish: an additional conservation risk for salmon. Conservation Biology 16, 1581-1587.

Levin, P. S., Zabel, R. W. \& Williams, J. G. (2001). The road to extinction is paved with good intentions: negative association of fish hatcheries with threatened salmon. Proceedings of the Roval Society of London Series B 268, 1153-1158.

Li, J. L., Cohen, Y., Schupp, D. H. \& Adelman, I. R. (1996). Effects of walleye stocking on population abundance and fish size. North American fournal of Fisheries Management 16, 830-839.

Liermann, M. \& Hilborn, R. (2001). Depensation: evidence, models and implications. Fish and Fisheries 2, 33-58.

Linnen, C., Tatar, M. \& Promislow, D. (2001). Cultural artifacts: a comparison of senescence in natural, laboratory-adapted and artificially selected lines of Drosophila melanogaster. Evolutionary Ecology Research 3, 877-888.
LoREnZEN, K. (1995). Population dynamics and management of culture-based fisheries. Fisheries Management and Ecology 2, 61-73.

LOREnZEN, K. (1996). The relationship between body weight and natural mortality in fish: a comparison of natural ecosystems and aquaculture. Fournal of Fish Biology 49 $627-647$.

LORENZEN, K. (2000a). Allometry of natural mortality as a basis for assessing optimal release size in fish stocking programmes. Canadian fournal of Fisheries and Aquatic Sciences 57, 2374-2381.

Lorenzen, K. (2000b). Population dynamics and management. In Tilapias: Biology and Exploitation (eds M. C. M. Beveridge and B. J. McANdrew), pp. 163-225. Kluwer, Dordrecht.

Lorenzen, K. (2005). Population dynamics and potential of fisheries stock enhancement: practical theory for assessment and policy analysis. Philosophical Transactions of the Royal Society B 360, 171-189.

LORENZEN, K. (2008a). Beyond 'stock and recruitment': density-dependent growth in recruited fish and its role in population regulation. Bulletin of Marine Science $\mathbf{8 1}$ $181-196$.

LORENZEN, K. (2008b). Understanding and managing enhancement fisheries systems. Reviews in Fisheries Science 16, 10-23.

Lorenzen, K., Garaway, C. J., Chamsingh, B. \& Warren, T. J. (1998). Effects of access restrictions and stocking on small water body fisheries in Laos. Fournal of Fish Biology 53 (Suppl. 1), 345-357.

Lorenzen, K., Leber, K. M. \& Blankenship, H. L. (2010). Responsible approach to marine stock enhancement: an update. Reviewes in Fisheries Science 18, 189-210.

Mackey, G., McLean, J. E. \& Quinn, T. P. (2001). Comparison of run timing, spatial distribution, and length of wild and newly established hatchery populations of steelhead in Forks Creek, Washington. North American fournal of Fisheries Management 21, 717-724.

Maclean, N. \& Laight, R. J. (2000). Transgenic fish: an evaluation of benefits and risks. Fish and Fisheries 1, 146-172.

Mair, G. G., Abucay, J. S., Abella, T. A., Beardmore, J. A. \& Skibinski, D. O. F (1997). Genetic manipulation of sex ratio for the large-scale production of all-male tilapia Oreochromis niloticus. Canadian Fournal of Fisheries and Aquatic Sciences 54, 396-404.

Malavasi, S., Georgalas, V., Lugli, M., Torricelli, P. \& Mainardi, D. (2004). Differences in the pattern of antipredator behaviour between hatchery-reared and wild European Sea bass juveniles. Fournal of Fish Biology 65 (Suppl. A), 143-155.

Margan, S. H., Nurthen, R. K., Montgomery, M. E., Woodworth, L. M. Briscoe, D. A. \& Frankham, R. (1998). Single large or several small? Population fragmentation in the captive management of endangered species. Zoo Biology 17, $467-480$.

McClure, M. M., Utter, F. M., Baldwin, C., Carmichael, R. W., Hassemer, P. F., Howell, P. J., Spruell, P., Cooney, T. D., Schaller, H. A. \& Petrowski, C. E. (2008). Evolutionary effects of alternative artificial propagation programs: implications for viability of endangered anadromous salmonids. Evolutionary Applications 1, 356-375.

McGinnity, P., Prodöhl, P., Ferguson, A., Hynes, R., Ó Maoiléidigh, N., Baker, N., Cotter, D., O’Hea, B., Cooke, D., Rogan, G., Taggart, J. \& Cross, T. (2003). Fitness reduction and potential extinction of wild populations of Atlantic salmon Salmo salar, as a result of interactions with escaped farm salmon. Proceedings of the Royal Society of London Series B 270, 2443-2450.

McVicar, A. H. (1997). Disease and parasite implications of the coexistence of wild and cultured Atlantic salmon populations. ICES Journal of Marine Science 54, $1093-1103$.

Medley, P. A. H. \& Lorenzen, K. (2006). EnhanceFish: A Decision Support Tool for Aquaculture-Based Fisheries Enhancement. Imperial College, London. Available at http://www.aquaticresources.org/enhancefish.html. Accessed 12 July 2010.

Mehner, T., Pohlmann, K., Elkin, G., Monaghan, M. T. \& Freyhof, J. (2009). Genetic mixing from enhancement stocking in commercially exploited vendace populations. Fournal of Applied Ecology 46, 1340-1349.

Metcalfe, N. B., Valdimarsson, S. K. \& Morgan, I. J. (2003). The relative roles of domestication, rearing environment, prior residence and body size in deciding territorial contests between hatchery and wild juvenile salmon. Fournal of Applied Ecology 40, 535-544

Mezzera, M. \& LARgiader, C. R. (2001). Evidence for selective angling of introduced trout and their hybrids in a stocked brown trout population. Fournal of Fish Biology 59, 287-301.

Miller, L. M. \& Kapuscinski, A. R. (2003). Genetic guidelines for hatchery supplementation programs. In Population Genetics: Principles and Applications for Fisheries Scientists (ed. E. M. Hallerman), pp. 329-355. American Fisheries Society, Bethesda.

Mobrand, L. E., Barr, J., Blankenship, L., Campton, D. E., Evelyn, T. T. P., Flagg, T. A., Mahnken, C. V. W., Seeb, L. W., Seidel, P. R. \& Smoker, W. W. (2005). Hatchery reform in Washington state: principles and emerging issues. Fisheries 30 (6), 11-23.

Mobrand, Jones and Stokes Associates (2006). The All-H Analyser (AHA) User Guide. Mobrand, Jones and Stokes Associates, Vashon.

Moyle, P. B. \& Light, T. (1996). Biological invasions of fresh water: empirical rules and assembly theory. Biological Conservation 78, 149-162. 
Muir, W. M. \& Howard, R. D. (2002). Assessment of possible ecological risks and hazards of transgenic fish with implications for other sexually reproducing organisms. Transgenic Research 11, 101-114.

Murray, A. G. \& Peeler, E. J. (2005). A framework for understanding the potential for emerging diseases in aquaculture. Preventive Veterinary Medicine 67, 223-235.

Naish, K. A., Taylor, J. E., Levin, P. S., Quinn, T.P., Winton, J. R., Huppert, D. \& Hilborn, R. (2008). An evaluation of the effects of conservation and fishery enhancement hatcheries on wild populations of salmon. Advances in Marine Biology 53, 61-194.

Naylor, R., Hindar, K., Fleming, I., Goldburg, R., Williams, S., Volpe, J., Whoriskey, F., Eagle, J., Kelso, D. \& Mangel, M. (2004). Fugitive salmon: assessing the risks of escaped fish from net-pen aquaculture. BioScience 55, 427-437.

Naylor, R. L., Williams, S. L. \& Strong, D. R. (2001). Aquaculture-a gateway for exotic species. Science 294, 1655-1666.

Nislow, K. H., Einum, S. \& Folt, C. L. (2004). Testing predictions of the critical period for survival concept using experiments with stocked Atlantic salmon. Fournal of Fish Biology 65 (Suppl. A), 188-200.

Norris, A. T., Bradley, D. G. \& Cunningham, E. P. (1999). Microsatellite genetic variation between and within wild and farmed Atlantic salmon (Salmo salar) populations. Aquaculture 180, 247-264.

Nostvik, F. \& Pedersen, T. (1999). Movement patterns and growth of wild cod (Gadus morhua L.) and hatchery-reared cod released as 1-group. In Stock Enhancement and Sea Ranching (eds B. R. Howell, E. Moksness and T. Svasand), pp. 315-333. Fishing News Books, Oxford.

Olesen, I., Groen, A. F. \& GJerde, B. (2000). Definition of animal breeding goals for sustainable production systems. Fournal of Animal Science 78, 570-582.

Olla, B. L., Davis, M. W. \& Ryer, C. H. (1998). Understanding how the hatchery environment represses or promotes the development of behavioral survival skills. Bulletin of Marine Science 62, 531-550.

Olsen, E. M., Heino, M., Lilly, G. R., Morgan, M. J., Brattey, J., Ernande, B. \& Dieckmann, U. (2004). Maturation trends indicative of rapid evolution preceded the collapse of northern cod. Nature 428, 932-935.

Owens, L. (2003). Diseases. In Aquaculture: Farming of Aquatic Animals and Plants (eds J. S. Lucas and P. C. Southgate), pp. 199-214. Blackwell Publishing, Oxford. Philippart, J. C. (1995). Is captive breeding an effective solution for the preservation of endemic species? Biological Conservation 72, 281-295.

Piferrer, F., Beaumont, A., Falguière, J. G., Flajšhans, M., Haffray, P. \& Соцомво, L. (2009). Polyploid fish and shellfish: production, biology and applications to aquaculture for performance improvement and genetic containment. Aquaculture 293, 125-156.

Policansky, D. (1983). Size, age and demography of metamorphosis and sexual maturation in fishes. American Zoologist 23, 57-63.

Ponzoni, R. W., Khaw, H. L., Nguyen, N. H. \& Hamzah, A. (2010). Inbreeding and effective population size in the Malaysian nucleus of the GIFT strain of Nile tilapia (Oreochromis niloticus). Aquaculture 302, 42-48.

Price, E. O. (2002). Animal Domestication and Behaviour. CABI Publishing, Wallingford.

Pulkinen, K., Suomalainen, L.-R., Read, A. F., Ebert, D., Rintamäki, P. \& Valtonen, E. T. (2010). Intensive fish farming and the evolution of pathogen virulence: the case of columnaris disease in Finland. Proceedings of the Royal Society $B$ 277, 593-600.

Reed, D. H. \& Frankham, R. (2003). Correlation between fitness and genetic diversity. Conservation Biology 17, 230-237.

REISENBiCHLER, R. R. (1988). Relationship between distance transferred from natal stream and recovery rate for hatchery coho salmon. North American fournal of Fisheries Management 8, 172-174.

ReisenbichleR, R. R. \& MCIntyre, J. D. (1977). Genetic differences in growth and survival of juvenile hatchery and wild steelhead trout. Fournal of the Fisheries Research Board of Canada 34, 123-128.

Reisenbichler, R. R. \& Rubin, S. P. (1999). Genetic changes from artificial propagation of Pacific salmon affect the productivity and viability of supplemented populations. ICES Journal of Marine Science 56, 459-466.

Reisenbichler, R. R., Utter, F. M. \& Krueger, C. C. (2003). Genetic concepts and uncertainties in restoring fish populations and species. In Strategies for Restoring River Ecosystems: Sources of Variability and Uncertainty in Natural and Managed Systems (eds R. C. Wissmar and P. A. Bisson), pp. 149-183. American Fisheries Society, Bethesda.

Richards, R. A. \& Rago, P. J. (1999). A case history of effective fisheries management: Chesapeake Bay striped bass. North American fournal of Fisheries Management 19, $356-375$.

RofF, D. A. (1992). The Evolution of Life Histories: Theory and Analysis. Chapman and Hall, New York.

Rose, K. A., Cowan, J. H., Winemiller, K. O., Myers, R. A. \& Hilborn, R. (2001). Compensatory density-dependence in fish populations: importance, controversy, understanding and prognosis. Fish and Fisheries 2, 293-327.

Ruesink, J. L. (2005). Global analysis of factors affecting the outcome of freshwater fish introductions. Conservation Biology 19, 1883-1889.

RymAN, N. \& LAIKRE, L. (1991). Effects of supportive breeding on genetically effective population size. Conservation Biology 5, 325-329.
Schisler, G. J. \& Bergersen, E. P. (2002). Evaluation of the risk of high elevation colorado waters to the establishment of Myxobolus cerebralis. American Fisheries Society Symposium 29, 33-41.

Sharma, R., Morishima, G., Wang, S., Talbot, A. \& Gilbertson, L. (2006). An evaluation of the Clearwater River supplementation program in western Washington. Canadian Fournal of Fisheries and Aquatic Science 63, 423-437.

SheA, K. \& Chesson, P. (2002). Community ecology theory as a framework for biological invasions. Trends in Ecology \& Evolution 17, 170-176.

Smith, T. D., GJørseter, J., Stenseth, N. C., Kittilsen, M. O., Danielssen, D. S., Solemdal, P. \& Tveite, S. (2002). A century of manipulating recruitment in coastal cod populations: the Flodevigen experience. ICES Marine Science Symposia 215, 402-415.

Soto, D., Jara, F. \& Moreno, C. (2001). Escaped salmon in the inner seas, southern Chile: facing ecological and social conflicts. Ecological Applications 11, 1750-1762.

Sosiak, A. J. R., Randall, G. \& McKenzie, J. A. (1979). Feeding by hatchery-reared and wild Atlantic salmon (Salmo salar) parr in streams. Fournal of the Fisheries Research Board of Canada 36, 1408-1412.

SRSRP (2004). Salmon Recovery Science Review Panel: Report for the Meeting held August 30September 2. Northwest Fisheries Science Center, National Marine Fisheries Service, Seattle. (online) available at http://www.nwfsc.noaa.gov/trt/rsrp_docs/rsrpreport sept30_2004e.pdf. Accessed 5 April 2009.

TACON, A. G.J. (1992). Nutritional fish pathology: morphological signs of nutrient deficiency and toxicity in fish. FAO Fisheries Technical Paper 330.

TACON, A. J. (2003). Aquaculture production trends analysis. FAO Fisheries Circular 886 (Rev. 2), 5-29.

Tanaka, M., Seikai, T., Yamamoto, E. \& Furuta, S. (1998). Significance of larval and juvenile ecophysiology for stock enhancement of the Japanese flounder, Paralichthys olivaceus. Bulletin of Marine Science 62, 551-571.

Tenhumberg, B., Tyre, A. J., Shea, K. \& Possingham, H. P. (2004). Linking wild and captive populations to maximize species persistence: optimal translocation strategies. Conservation Biology 18, 1304-1314.

Theriault, V., Moyer, G. R., Jackson, L. S., Blouin, M. S. \& Banks, M. A. (2011). Reduced reproductive success of hatchery coho salmon in the wild: insights into most likely mechanisms. Molecular Ecology 20, 1860-1869.

Thorpe, J. E. (1991). Acceleration and deceleration effects of hatchery rearing on salmonid development and their consequences for wild stocks. Aquaculture 98, $111-118$.

Thorpe, J. E. (2004). Life history responses of fishes to culture. Fournal of Fish Biology 65 (Suppl. 1), 263-285.

Thrower, F. P., Hard, J. J. \& Joyce, J. E. (2004). Genetic architecture of growth and early life-history transitions in anadromous and derived freshwater populations of steelhead. Journal of Fish Biology 65 (Suppl. A), 286-307.

Townsend, C. R. (2003). Individual, population, community, and ecosystem consequences of a fish invader in New Zealand streams. Conservation Biology 17, $38-47$.

UtTer, F. (2004). Population genetics, conservation and evolution in salmonids and other widely cultured fishes: some perspectives over six decades. Reviewes in Fish Biology and Fisheries 14, 125-144.

UtTer, F. \& EpIfanio, J. (2002). Marine aquaculture: genetic potentials and pitfalls. Reviews in Fish Biology and Fisheries 12, 59-77.

Van Poorten, B. T., Arlinghaus, R., Daedlow, K. \& Heartel-Borer, S. S. (2011). Social-ecological interactions, management panaceas, and the future of wild fish populations. Proceedings of the National Academy of Sciences 108, 12554-12599.

VERSPOOR, E. (1988). Reduced genetic variability in first-generation hatchery populations of Atlantic salmon (Salmo salar). Canadian Fournal of Fisheries and Aquatic Sciences 45, 1686-1690.

WAGNER, E. J. (2002). Whirling disease prevention, control, and management: a review. American Fisheries Society Symposium 29, 217-225.

Walker, A. M., Beveridge, M. C. M., Crozier, W., O’Maoleidigh, N. \& Milner, N. (2006). Monitoring the incidence of escaped farmed Atlantic salmon, Salmo salar L., in rivers and fisheries of the United Kingdom and Ireland: current progress and recommendations for future programmes. ICES Journal of Marine Science 63, $1201-1210$.

Walters, C. \& Kitchell, J. F. (2001). Cultivation/depensation effects on juvenile survival and recruitment: implications for the theory of fishing. Canadian Fournal of Fisheries and Aquatic Sciences 57, 39-50.

WAPLES, R. S. (1999). Dispelling some myths about hatcheries. Fisheries 24 (2), $12-21$.

WARD, R. D., Woodwark, M. \& Skibinski, D. O. F. (1994). A comparison of genetic diversity levels in marine, freshwater and anadromous fishes. Journal of Fish Biology 44, 213-232.

Weber, E. D. \& FAusch, K. D. (2003). Interactions between hatchery and wild salmonids in streams: differences in biology and evidence for competition. Canadian Journal of Fisheries and Aquatic Sciences 60, 1018-1036.

Wedekind, C. (2002). Sexual selection and life-history decisions: implications for supportive breeding and the management of captive populations. Conservation Biology 16, $1204-1211$. 
Weir, L. K., Hutchings, J. A., Fleming, I. A. \& Einum, S. (2004). Dominance relationships and behavioural correlates of individual spawning success in farmed and wild male Atlantic salmon, Salmo salar. Fournal of Animal Ecology 73, 1069-1079.

Welcomme, R. L. (1988). International introductions of inland aquatic species. FAO Fisheries Technical Paper 294.

Welcomme, R. L. \& Bartley, D. M. (1998). Current approaches to the enhancement of fisheries. Fisheries Management and Ecology 5, 351-382.

Welcomme, R. L., Cowx, I. G., Coates, D., Béné, C., Funge-Smith, S., Halls, A. S. \& Lorenzen, K. (2010). Inland capture fisheries. Philosophical Transactions of the Royal Society B 365, 2881-2896.

Williamson, M. (1996). Biological Invasions. Chapman \& Hall, London.

Wilson, A. J., Réale, D., Clements, M. N., Morrissey, M. M., Postma, E., Walling, C. A., Kruuk, L. E. B. \& Nussey, D. H. (2010). An ecologist's guide to the animal model. Fournal of Animal Ecology 79, 13-26.
Woodworth, L. M., Montgomery, M. E., Briscoe, D. A. \& Frankham, R (2002). Rapid genetic deterioration in captive populations: conservation implications. Conservation Genetics 3, 277-288.

Young, M. K., Haring, A. L., Rosenlund, B. \& Kennedy, C. (2002). Recovery History of Greenback Cutthroat Trout: Population Characteristics, Hatchery Involvement, and Bibliography. RMRS-GTR-88WWW. U.S. Department of Agriculture, Forest Service, Rocky Mountain Research Station, Fort Collins. Available at http://www.fws.fed.us/rm/pubs/rmrs_gtr88/. Accessed 7 November 2009.

Youngson, A. F., Dosdat, A., Saroglia, M. \& Jordan, W. C. (2001). Genetic interactions between marine finfish species in European aquaculture. Fournal of Applied Ichthyology 17, 153-162.

Zohar, Y. \& Mylonas, C. C. (2001). Endocrine manipulations of spawning in cultured fish: from hormones to genes. Aquaculture 197, 99-136.

(Received 7 April 2010; revised 29 November 2011; accepted 8 December 2011; published online 5 Fanuary 2012) 